\title{
AN INQUIRY-BASED MODELING APPROACH TO DEVELOPING GRAPHING SKILLS IN SEVENTH GRADE BIOLOGY
}

\author{
A Project Presented to the Faculty of \\ the Division of Education and Social Sciences \\ In Partial Fulfiliment \\ of the Requirements for the Degree of \\ Masters of Arts in Education \\ Emphasis: General Professional Development Track \\ by \\ Diana Bou Hamdan \\ Under the Direction of \\ Dr. Tamer Amin
}

\section{LEBANESE AMERICAN UNIVERSITY}

June, 2010 
Developing Graphing Skills in Seventh Grade Biology 
- LAU

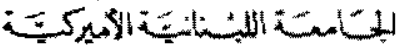

Lebanese American University
LEBANESE AMERICAN UNIVERSITY

School of Arts \& Sciences - Beirut Campus

\section{Project Approval Form}

Student Name: _Diana Bou-Hamdan

I.D. \#: 200801064

Project Title : An Inquiry-based Modeling Approach to Developing Graphing Skills in Seventh Grade Biology

Program / Department: Education

School: Arts \& Sciences, Beirut

Approved by:

Project Advisor: Tamer G. Amin

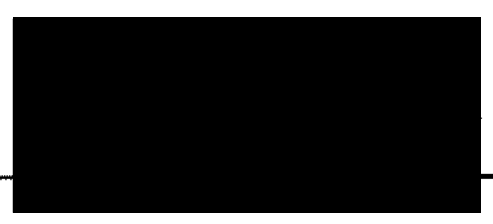

Committee Member: Iman Osta

Date: June $2^{\text {nd }} \cdot 2010$ 


\section{Plagiarism Policy Compliance Statement}

I certify that I have read and understood LAU's Plagiarism Policy. I understand that failure to comply with this Policy can lead to academic and disciplinary actions against me.

This work is substantially my own, and to the extent that any part of this work is not my own I have indicated that by acknowledging its sources.

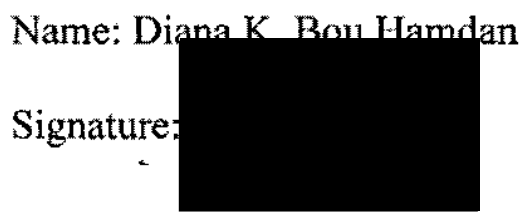

Date: June, 2010 
I grant to the LEBANESE AMERICAN UNIVERSITY the right to use this work, irrespective of any copyright for the University's own purpose without cost to the University or to its students and employees. I further agree that the university may reproduce and provide single copies of the work to the public for the cost of reproduction. 
Developing Graphing Skills in Seventh Grade Biology iii

\section{Acknowledgement}

I would like to acknowledge my supervisor, Dr. Tamer Amin, whose expertise, patience and knowledge added significantly to my graduate experience. I would also like to acknowledge my committee member, Dr. Iman Osta, for her comments and for her time. Finally I would like to thank my family for their support and encouragement. 


\section{Table of contents}

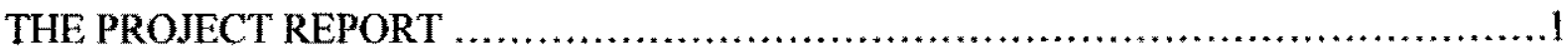

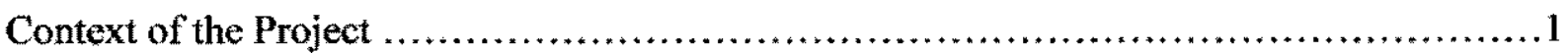

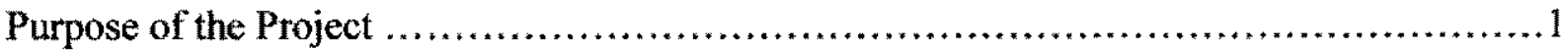

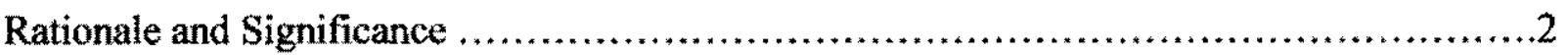

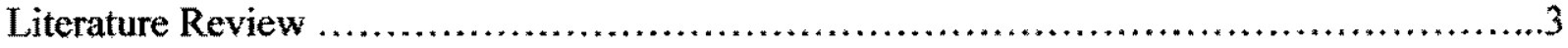

Problems students face with graphing ....................................................

Problems noted by teachers in the Lebanese context ............................

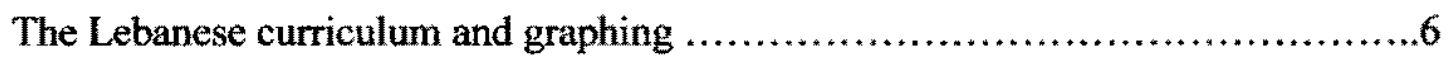

Teaching methods used in the Lebanese school ................................

A new approach to teaching graphing through scientific modeling: An inquiry-based

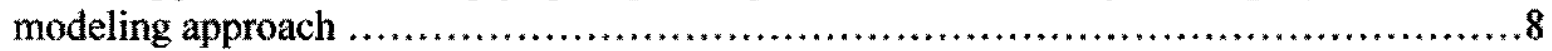

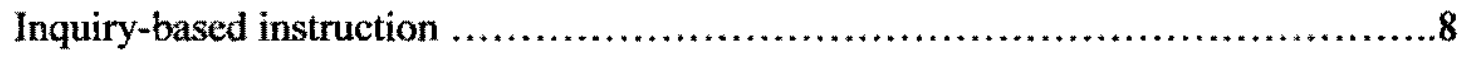

Modeling and metamodeling knowledge .......................................

Coupling modeling and inquiry-based instruction in science .......................................10

Modeling focusing on graphing ..........................................................12

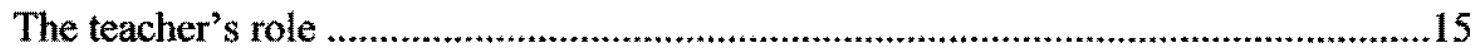

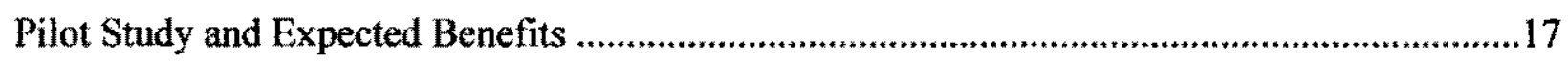

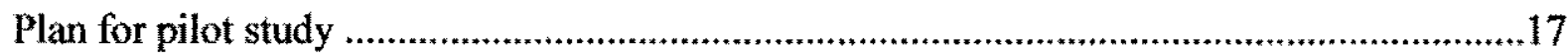

Findings and expected benefits .......................................................................................18

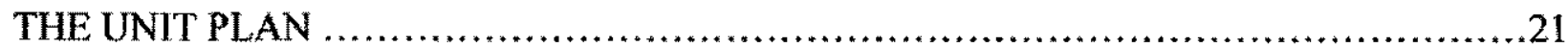

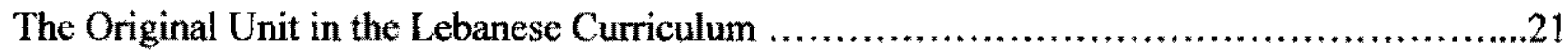

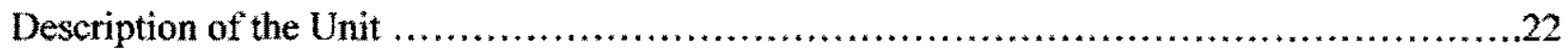

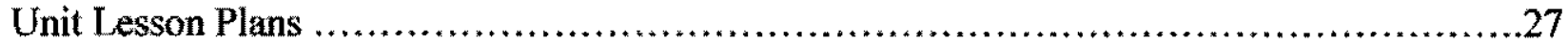

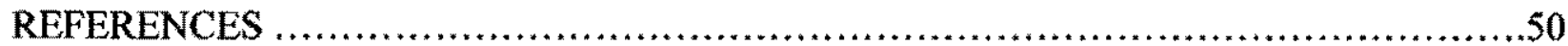




\begin{abstract}
Modeling is a major aspect of science, and graphing is an abstract form of modeling that is widely used in education. One of the teaching approaches that can be implemented in a science classroom to improve students' graphing skills is the Inquiry-Based Modeling Approach (IBMA). The purpose of the project was to redesign a biology unit adopting IBMA and aiming to improve grade 7 students' graphing skills. The unit was redesigned based on Lehrer's data display construct. This project was executed in the Lebanese context where there is inadequate emphasis on developing graphing skills. In such a context where memorizing the content is the major emphasis, students face many problems with graph construction and interpretation. A pilot study was conducted on three grade 7 students to examine the feasibility of the redesigned unit. The students were pre-tested and post-tested and the results were compared. Comparing the tests' results showed that grade 7 students' graphing skills improved and that they were able to appreciate the value of graphs more after the unit implementation.
\end{abstract}

Keywords: modeling, graphing, inquiry, data display. 


\title{
THE PROJECT REPORT
}

\author{
Context of the Project
}

The present project was executed in the Lebanese context. Although the general objectives of the Lebanese science curriculum state that students should investigate and discover knowledge for themselves, in Lebanese classrooms students are mostly treated as passive learners. Moreover, the Lebanese science curriculum focuses on content, with inadequate emphasis on developing various scientific skills such as modeling. Modeling is a fundamental aspect of science; therefore science educators should enhance students' ability to construct and interpret models as a major objective of science and math education. Scientific models include different forms, one of which is graphs that are of great use in mathematics and science.

Graphing is a method by which people represent relationships between variables and then use those representations to draw conclusions about the relationships. However, in the Lebanese curriculum graphs are represented as minor activities, and the focus is on content knowledge rather than graphing as a tool for scientific investigations and for developing various scientific process skills.

\section{Purpose of the Project}

The purpose of this project has two components. The first component is to redesign a biology unit adopting inquiry-based modeling approach (IBMA) aiming to improve grade 7 students' graphing skills, focusing in particular on graph construction and interpretation. The second component is to pilot the feasibility of the redesigned unit. The pilot study was conducted with three grade 7 students who were pre- and post-tested, and then interviewed. The tests and the interviews provide information about the viability, applicability and effectiveness of the redesigned unit. 


\section{Rationale and Significance of the Project}

Redesigning a biology unit is of value since students face various types of problems with modeling, particularly graphing. Learners show various systematic errors in constructing and interpreting graphs. Those errors tend to mislead them when drawing conclusions in different subject areas. At the level of interpreting graphs, errors are due to inherent biases and limitations of individual's perception (Shah \& Hoeffner, 2001). For instance, some students tend to group a set of points in a line graph rather than thinking of other possible ways of grouping such as a bar graph. For this purpose a student is required to understand different forms and uses of graphs. Moreover learners typically depend on appearance to interpret graphs without appreciating that graphs are models that represent data more abstractly. At the level of constructing and performing operations with graphs, students face great difficulties in certain areas such as reading and selecting points. That is, learners have difficulty reading points on the graph especially in the absence of some numbers on the axes, when the point falls between gridlines, or in the absence of the gridlines (Forster, 2002).

IBMA was selected as an approach to redesign a grade 7 biology unit since the process of modeling is critical in science. When including modeling in inquiry-based instruction, learners will feel involved in the investigation process and they will be motivated to construct graphs and draw conclusions from them. This motivation will lead the students towards concentrating on graphical representations and their critical role in the process. As a result, they will have to decide on the appropriate scale, the $x$-axis and the $y$-axis attributes, the outliers, the correct type of the graphical representation, and the shape of the graph. Eventually, if those steps are applied with deep understanding of the whole process, then students will be able to draw conclusions and answer the main question driving the inquiry. Therefore, instead of incorporating graphs as minor activities that only require naïve knowledge about graphing skills, students will have the 
opportunity to construct and interpret graphs as tools that will help them reach plausible solutions to the raised questions. When implementing IBMA, students will be involved in the scientific process and they will appreciate the value of graphing as a very useful method available for answering scientific questions.

\section{Literature Review}

Modeling is a fundamental aspect of science; therefore science educators should implement model-based instruction that develops students' modeling skills (Schwarz \& White, 2005). Scientific models can take different forms; they can either be models of systems such as a 3D representation of the solar system, a computer simulation, quantitative laws, or qualitative principles, or graphs. Graphing is a method by which people represent relationships between variables and then use those representations to draw conclusions about these relationships. Graphs are present in several domains of our daily lives in journals, internet, TV and newspapers. In such domains, an individual handles graphs in what Gal (2002, as cited by Monteiro \& Ainely, 2003) identifies as a reading context where graphs are read and interpreted. In an inquiry context, individuals such as students and scientists act as data producers and analyzers drawing conclusions from their own data representations and then reporting their findings (Monteiro \& Ainely, 2003). Preparing individuals that are capable of constructing and interpreting graphs is a fundamental task that has to emerge early in school contexts. Unfortunately, this is often not the case despite its official inclusion in mathematics and science curricula. Recently, various researches in science and mathematics education have been focusing on the development of new approaches to integrate students more in the teaching/learning process. Some of this research emphasizing modeling focuses on improving students ${ }^{*}$ graphing skills in inquiry-based classroom instruction where students collect, represent, and interpret data. Developing students' graphing skills is a challenge, as documented by research and frequently 
noted by teachers. Based on this, teachers are required to be aware of various problems that students face with graphing.

Problems students face with graphing

Learners show various systematic errors in constructing and interpreting graphs; those errors tend to mislead them in drawing conclusions in different subject areas. While the construction of graphs consists of using a correct scale, choosing the proper attributes that represent the $x$-axis and the $y$-axis, and finding specific points on the graph, interpreting graphs requires that students consider the whole data representation with all the information it provides, in order to draw conclusions. At the level of interpreting graphs, errors are due to inherent biases and limitations of individual's perception (Shah \& Hoeffner, 2001). Learners frequently depend on their graph schema which is their general knowledge about graphs, to draw the implications of a certain display; however this practice might not be effective when dealing with novel or complex displays. Moreover learners typically depend on appearance to interpret graphs without appreciating that graphs are models that represent data more abstractly. That is, they identify vertical bars as better representatives of quantities of physical material, whereas horizontally oriented bars as better representatives of other data such as distance covered. As stated by Shah and Hoeffner (2001), viewers mostly expect the $x$-axis to represent independent variables and the $y$-axis to represent dependent ones, and they might also assume that a greater slope always implies higher value rather than different pace of change. When dealing with data retrieval from different forms of graphs learners tend to make conclusions about $x-y$ trends more accurately from line graphs than bar graphs. Even in line graphs they tend to describe data as continuous e.g. "The more male a person is the taller he/she is" (Zacks \& Tversky, 1999, as cited by Shah and Hoeffner, 2001, p. 52). 
At the level of constructing and performing operations with graphs, students face great difficulties in certain areas. Learners have difficulty reading points on the graph especially in the absence of some numbers on the axes, when the point falls between gridlines, or in the absence of the gridlines (Forster, 2002). Students are also confused by the selection of points when calculating a slope and by the importance of this slope. In constructing a line of good fit starting with scattered points, students tend to choose points lying outside the line when calculating the slope. Finally when asked to construct a line passing through the origin and having a certain slope, students tend to disregard the usefulness of the gradient which leads to an inappropriate line steepness (Forster, 2002).

Those are the main errors encountered by students in general, they have been tested and reported by different individuals in different areas, so what is the case in the Lebanese context?

Problems students face with graphing in the Lebanese context

\section{Problems noted by teachers in a Lebanese middle school.}

In this section I rely on personal communication with Lebanese teachers and grade seven students, due to the absence of research on the graphing skills of the Lebanese students. I asked two teachers, a mathematies teacher and a physics teacher, about the common problems their students encounter with graphing. The mathematics teacher has been teaching middle school for 10 years and is a math major graduate. The physics teacher has been teaching middle school for 12 years and is a physics major graduate. The physics teacher states that her students struggle with using the correct scale on the graph (Personal communication, Feb., 2010). Accordingly they get confused when given two different scales for the $x$ - and $y$-axis, so the teacher decides to draw the $y$-axis for them with its scale and asks them to only represent the $x$-axis. Similar to what Shah and Hoeffner (2001) described in their study, this teacher also reported that her 
students rely on the graph appearance when interpreting results. They find it difficult to understand that the $\mathrm{x}$-axis could be an altitude where they see it as a horizontal line parallel to the ground. In Mathematics, students seem to have fewer problems. In their mathematics class, seventh graders in this school are not facing any problems with graphs: they are able to construct them, find points on them, and decide on the right scale; however, transforming percentages into numbers to be represented graphically seems to be problematic for them (Personal communication, Feb., 2010). Both teachers mentioned that they usually assign those tasks to students with minimum difficulty and maximum clarity. It's interesting that while grade 7 students can use the proper scale on a given graph in mathematics, they find this task complicated in physics. When some of the students in grade 7 were asked about this fact they mentioned that the data given to them in mathematics are easy to scale and represent graphically. They are given whole numbers with equal intervals such as $5,10,15,20,25 \ldots$ On the other hand, in physics the numbers given are mainly decimals and with variable intervals such as 1.2 , 3.4, 5.6... (Personal communication, Feb., 2010).

\section{The Lebanese curriculum and graphing.}

In the Lebanese National Curriculum (Center of Educational Research and Development, 1997), one of the mathematics general objectives addresses the need to train highly qualified workers and researchers. This is achieved by providing students with the opportunity to engage in scientific inquiry and improve research skills in order to create relations between mathematics and real life (Center of Educational Research and Development, 1997). In the scope and sequence of the units, statistics is included as a section of the mathematics curriculum in the second cycle (fourth, fifth, and sixth grades). In the fourth grade students are taught how to collect and organize data. In the fifth grade they are expected to record findings in three different graphical forms: pictographs, bar graphs, and tile graphs. Data interpretation is introduced in 
grade six and it focuses on data represented in circular diagrams. The statistics unit in the middle school is represented under "Handling Data" where students get to know various graphing forms in grade 7 , and frequencies, mean and weighted mean by the end of the intermediate level. In the science curriculum (Center of Educational Research and Development, 1997), encouraging learners to use scientific knowledge and skills in everyday life is one of the general objectives. Looking closely at the grade 7 biology curriculum, reveals that handling graphs is a major element of the "Activities" section rather than the "Learning objectives" section (Jammal, Dagher, Dakroub, \& Ghazali, 2000). Basically analyzing graphs and tabulated data, or simply reading the data represented by those displays is one of the main activities in each chapter of this book. This activity appears six times in grade 7 biology program consisting of 11 topics, whereas interpreting graphs and inferring conclusions from them, appears only once in the same program. Based on this we might infer that at this grade level, constructing and analyzing graphs are represented as additional activities not as major objectives.

\section{Teaching methods used in the Lebanese school.}

The information presented in this section is based on informal personal observations I performed in grades 7 and 11 in a rural Lebanese school. I attended five biology lessons at each grade level, observed the teaching methods, and used notes as my observational tool. The typical classroom in the context of most of the Lebanese schools is based on teacher-led instruction with small groups of students doing seatwork, and taught to speak only after being given permission by the teacher. In such environments, students don't have the opportunity to think or discuss matters as active members of a community. Similarly, the procedure followed to teach graphs is traditional where the teacher lectures and the students learn by rote, that is leaning new information involves memorization with little understanding and with minimum practice (personal classroom observations, Feb., 2010). This is confirmed by what BouJaoude (2002) 
presents in his study about the balance of the scientific literacy themes in the Lebanese science curriculum. In this study, BouJaoude (2002) states that although science as a means of knowing appears in the general objectives of the science curriculum, it is not emphasized at the classroom level. Therefore students are not provided with the essential tools to reflect upon science and to understand the nature of scientific observations and the different relationships.

Addressing graphing errors that students make and the problematic attention to graphing in the Lebanese curriculum motivates the implementation of a new innovative approach to developing graphing skills in middle school.

A new approach to teaching graphing through scientific modeling: An inquiry-based modeling approach

\section{Inquiry-based instruction.}

Researchers in science education frequently discuss and evaluate inquiry teaching methods and recommend their appropriate implementation. According to Anderson (2007) inquiry is a basic method that is advised to be used for the implementation of science curricula at any level. Using inquiry to introduce students to scientific topics improves students' achievement and their problem solving. Ayoubi and BouJaoude (2005, as cited by BouJaoude, 2007) suggest that good science teaching is based on inquiry that emphasizes both content and process, relates content to students' prior experiences, motivates students to discover and question the world around them, and develops their communication skills. The main aim of inquiry teaching is to develop learners' higher order critical thinking skills, and to offer them an opportunity for indepth understanding of content (Rensik, 2001 as cited by BouJaoude, 2007). 
Many researchers have been working on inquiry in various content areas. For instance, BouJaoude (2007) summarizes the five steps of the inquiry model, those are: identifying the problem, forming a hypothesis, gathering data, assessing the hypothesis, and finally generalizing. Similarly White (1998) distinguishes two common approaches: top-down approach and bottomup approach. The former suggests providing students with a law and asking them to solve a set of problems based on this law. On the other hand, the bottom-up approach demands that students observe the real world in order to induce a law. The problem with those two approaches, as stated by White (1998), is that they present a big gap between the real world and the abstract representations of laws. The best approach according to White (1998) that can be applied instead is the middle-out approach, illustrated by a 4-step instructional model or four-phase inquiry cycle, where laws are used by students to predict what will subsequently happen. The cycle is initiated by motivating students to select a hypothesis and then perform group investigations, until they reach the final phase where they conclude the accuracy of the laws they formalized.

This project redesigns a biology unit using an Inquiry-Based Modeling Approach. This type of instruction has been researched in various educational areas and is largely illustrated in Lehrer's work on data display representation and interpretation. Initially it's significant to address students' awareness of the nature and the role of scientific models that they should develop while performing operations with models.

Modeling and metamodeling knowledge.

The process of modeling is critical in science. Models are perceived as "... systems of elements, operations, relationships, and rules that can be used to describe, explain, or predict the behavior of some other familiar systems" (Doerr \& English, 2003, p. 112). In order to deeply understand scientific phenomena students must be introduced to different types of models, 
whether concrete such as an elbow model or abstract such as graphical representation of collected data. Students' knowledge and understanding of any scientific phenomenon is revealed by the models they develop, whether abstract or concrete (Wilson, Shulman, \& Richert, 1987, as cited by Mendez, Sherin, \& Louis, 2007). Based on this, students should understand the processes of science and the nature and role of scientific models, which is referred to as metamodeling knowledge (Schwarz \& White, 2005). According to Schwarz and White (2005) without the metamodeling knowledge students will neither develop a full understanding of science nature nor will they be able to create scientific models and evaluate them. The metamodeling knowledge is viewed at four different levels. First, the nature of a model, where the learner has to think about the kind of a model and its attributes, what this model represents, the availability of several models for one phenomenon, and to what extent this model represents the real world. Second, the process of modeling, that involves thinking about the elements engaged in the process, the design of the model, and the possibility of altering or modifying this model. Third, model evaluation, which indicates the criteria necessary to select one model and discard another. Finally, the model's purpose, which entails deciding on the purpose of the utilized model, and its usefulness in a science investigation (Schwarz \& White, 2005). Subsequently, we will tackle different approaches by which Lehrer and his colleagues couple modeling and inquiry.

\section{Coupling modeling and inquiry-based instruction in science.}

According to Lehrer and Schauble (2000) students need to explore and evaluate different forms and functions of models by practicing modeling systematically, extending early competencies into more complex ones. In modeling classrooms students experience intelligent discourse and debate about scientific matters and skills. Such classrooms also enrich instruction with the excitement of learning about real-world phenomena (Jackson, Dukerich, \& Hestenes, 
2008). Creating a modeling curriculum requires finding the most appropriate entry point for inexperienced children, then considering the progression of tasks reflecting a developmental taxonomy of models, and finally selecting the modeling practices that would adequately capture the full sweep of the modeling land scope (Lehrer \& Schauble, 2000). Two entrance points show the relation between the real world and the model representing it. The easiest entrance is the resemblance-similarity entrance either through physical microcosms which are identical to the real world (such as an elbow model showing the function and the form of a real elbow) or through representational systems (such as maps and diagrams). More advanced modeling of the real world involves relational structure-analogy reflected in syntactic models and hypotheticaldeductive models. The former is applied by moving away from the resemblance end towards the analogy end where models represent system functions without any similarity between the model and the real world (such as modeling a bird seeking two different kinds of seeds by repeated random coin flips). The latter is the most challenging for students where they are expected to model the unobservable hypothetical entities that interact to produce a certain behavior or phenomenon. For example, billiard balls can be used to represent gas behavior where the force with which those balls hit the table sides increases as their speed of collision increases.

An approach developed by Jackson, Dukerich, and Hestenes (2008) is a modeling process focusing on enhancing students' modeling skills in class instruction based on inquiry. The first stage of this process is model development; this stage begins with a class discussion or demonstration in order to reach common grounds for a raised question. Later students form small groups to try to find an answer to the question through designing experiments or models, and finally they are expected to represent their solutions orally and in a written form. Model deployment is the second stage that implies applying the newly-discovered models to other 
situations in order to deepen their understandings. Finally, students are expected to complete worksheets in small groups and defend their results before their peers.

These modeling methods help in correcting many misconceptions and weaknesses of the traditional instructional approach, such as knowledge fragmentation, students' passivity, and the continual naĩve beliefs about the real world. If modeling is included in an inquiry-based context, students will be able to make sense of the physical world, understand scientific concepts, develop their own opinions and defend them, and evaluate results and conclusions in the presence of a justified belief (Jackson, Dukerich, \& Hestenes, 2008). Modeling and inquiry are recent trends in science education, but can this approach be used to develop graphing skills?

\section{Modeling focusing on graphing.}

As illustrated previously by Lehrer and Schauble (2000), to model the real world one should start at the resemblance-similarity entrance. After being knowledgeable about this concrete level of modeling, a student then can progress towards a more abstract modeling system, the relational structure-analogy. This system includes graphs that are syntactic abstract models. In a middle school science class, graphs can be integrated into the instruction in an attempt to develop students" graphing skills. Prior to enhancing such skills it is essential to discover the learners' level of graphical knowledge and expertise. For this purpose Lehrer provides us with two methods. The first is the "Data display construct" (see Appendix A for the "Data display construct") which is a scale showing the progression of data perception, particularly the various ways that students might think about constructing or interpreting a given data display in order to better understand the phenomenon. This construct is divided into six levels starting at the level of a case-specific view of a display (DaD1A) and moving up towards an aggregate perspective of this display (DaD6A). The second is "Meta Representational Competence" (MRC), a list that refers to the progression of students' understanding about the 
different forms and roles of displays covering the creation, interpretation, and comprehension of those forms. Lehrer and Schauble (2002) declare that developing students' graphing expertise requires building up their abilities to raise and investigate questions, to construct and structure data, to represent and analyze data, and to develop and support certain claims and reasoning chains.

Those skills involve repeated opportunities for students over the course of schooling to work with and apply a novel data modeling approach consisting of five phases. The first phase of this approach involves stating a suitable research question which is important since it focuses learners' attention on certain types of data and not on others. All research questions must specify the object of study and focus on attributes of those objects and how they vary.

The second phase is making sense of data that starts with defining and measuring attributes which "... is a major accomplishment and one that takes time and effort" (Lehrer \& Schauble, 2002, p. 2). For instance a study performed on fifth graders who worked with Wisconsin Fast plants revealed that the students were confused about which attribute to choose in order to measure the plant growth. After several discussions they decided to consider the height as the attribute they would measure. Later those attributes needed to be organized in categories that can summarize the collection's variability. The next step in this phase is structuring the defined data, where two basic types of information are required: what is studied and what are the terms describing it? The data table is one form for structuring data where the rows consist of cases and the columns of the variables. Finally in this phase, is the objectifying step which is illustrated by treating data as objects i.e. counting and manipulating them, determining relationships, and asking new questions of the existing data instead of collecting new data (Lehrer \& Schauble, 2001). 
The third phase in this process is "representing and visualizing data". Data might be represented in different forms of displays depending on the information one is seeking. Frequency tables and bar graphs are forms of displays that represent categorical information, pie charts show relative proportions of unequal base rates, frequency distributions provide information about frequency and degree of cases within one continuous variable, displays that help in investigating relationships such as line graphs that illustrate change in a single variable with time, data tables used to get familiar with a set of data, and lastly maps, pictures and other data displays.

The fourth phase is summarizing the data by representing what's typical about it via center indicators: mean, median, and mode. To choose the convenient indicator for a given set of data one should consider three issues: the type of information on which the data is based, data distribution, and the addressed question. This also requires information about data distribution or what's also known as the general shape.

The fifth phase in the process is making predictions and fitting the model to the data. This phase might be surprising to students; for instance when third graders were asked to predict their heights as adults, after studying their rate of growth from birth until present time, they concluded that if they continued to grow at the same rate they will be giant individuals at age 25 which shows a mismatch between the phenomenon and the model (Lehrer \& Schauble, 2001).

The five phases represented above are the major components of the data modeling approach, where understanding the problem and discussing it in an inquiry-based environment is a prerequisite for starting to think about any feasible solution (Lehrer \& Schauble, 2004). Similarly, enhancing graphing skills can be achieved through a " 2 cycle inquiry" procedure (Lehrer, Schauble, \& Petrosino, 2001). In the first cycle children who had experience with 
coordinate plots pose a question and draw a "prediction graph"; later they observe a real world phenomenon, record data, make use of different inscriptional forms, and then compare the real graph to the "prediction graph". If similarity is absent between those graphs learners are to conduct further investigations, and observe and compare different plots. The second cycle consists of considering more attributes of a phenomenon, conducting an experiment, predicting outcome, observing, comparing and sharing results. Implementing such approaches at any grade level highlights the necessity of having well-prepared skillful teachers who are able to motivate learners' involvement in discussion and application.

\section{The teacher's role.}

A skilled teacher's involvement is a fundamental requirement for the success of an inquiry-based modeling approach. Teachers here act as facilitators of the process. This will require adequate "Pedagogical Content Knowledge" (PCK) including sufficient subject matter knowledge (Treagust, 2007). BouJaoude (2007) agrees that the teacher's role in the inquiry process involves planning the various aspects of the unit and guiding students through investigations, insuring that the investigations are being planned and implemented carefully while identifying alternative sources of data, and encouraging students to reflect on different aspects.

Motivating learners to represent data and to think of various ways to modify them so that they are represented in the most convenient way possible, requires expert guidance from teachers. Based on this teachers should undergo meaningful professional development which is a complex and a multifaceted process (Lehrer \& Schauble, 2000). It involves developing teachers' knowledge of the subject matter, their knowledge of the way learners think and their knowledge of different pedagogical strategies. Besides this professional development, five categories of "design tools" are suggested: the task, that includes the form and the content of the 
activities; the tools such as rulers, computers, and lab equipment; inscriptions and notations which are characterized by graphs, maps, and mathematical formulae; the activity structure that includes laboratory investigations; and finally the modes and means of argumentation represented by grounds for a claim and ways to evaluate them. An expert teacher can also guide learners" discussions by "Socratic" questioning (Jackson, Dukerich, \& Hestenes, 2008). In "Socratic" questioning answers are drawn out from pupils in order to test accuracy and completeness in students' thinking and to move them towards their ultimate goal. There are various types of "Socratic" questions. The conceptual clarification questions where the teacher motivates the learner to think more about his/her own question. This is done by raising questions such as "Why are you stating that?"Another type is known as the probing assumptions that include questions such as "What else could you suggest?" Questioning viewpoints and perspectives is another type which is applied by using questions such as "Who benefits from this?" Additionally there are questions about the question "Why did we raise this question?" When it comes to teaching graphing skills, teachers should recognize that it is not a spontaneous action though it has to be meaningful and purposeful for learners. In this manner teachers should represent graphs as a succession of several tasks including having the students appreciate the need to construct graphs as a tool to solve a specific problem, choosing the suitable graphical form, drawing axes, plotting points, scaling, and drawing conclusions (Monteiro, \& Ainley, 2003).

Conclusion

Students should no longer be considered passive receivers of information. They are curious inquisitive learners that don't accept ideas and concepts without knowing their origins and their best ways of usage. They come to classrooms with prior knowledge some of which are misconceptions that they tend to believe in. For those students to learn science and other subjects 
in the most beneficial way possible allowing them to become future scientists and mathematicians and to construct and communicate knowledge properly and effectively, we should start considering innovative instructional approaches. One of those approaches is IBMA that encourages the integration of math in science, and stresses the importance of building an inquiry-based environment that allows students' engagement in the learning/teaching process. Such approaches are meant to be implemented as early as grade 2 . Constructing and interpreting graphs is one skill that might be developed in a science class following IBMA. Different levels of data display interpretation and construction should be defined at a certain grade level before introducing such an approach for assuring its proper implementation. Based on the above literature review and the discussion of innovative approaches in science, it is expected that a biology unit introduced using IBMA would improve grade 7 students' skills in constructing and interpreting graphs.

\section{Pilot Study and Expected Benefits}

Plan for pilot study

In order to get an initial sense of the feasibility of the redesigned lessons they were implemented with three of grade 7 students. Those students were also pre-tested and post-tested and the results were compared in order to measure the development in their graphing skills. Finally they were individually interviewed using open-ended questions. Those questions aim to investigate which method, the traditional or the experimental method, they favor and find more beneficial for developing their graphing skills.

The pre-test was administered to the students prior to implementing the redesigned unit (see Appendix B for pre-test and rubric). This pre-test consisted of two items: the first focused on students' ability to draw conclusions from a given display, while the second focused on 
students' ability to construct a line graph starting with tabulated data as an attempt to find the missing data and to draw conclusions. The content was different from what they studied in the biology unit. It addressed something related to a situation faced in everyday life.

Following instruction students were post-tested; the post-test consists of three extensive items (see Appendix $\mathrm{C}$ for post-test and rubric). The first was a multiple choice item which assessed students' knowledge about the biology unit introduced to them. The second item was similar to the pre-test part which assessed students' ability to draw conclusions from a data display but with a content related to their biology lesson. The third one tested the students" ability to construct a line graph and to infer conclusions based on content related to what they've covered in the class.

The rubrics of the pre-test and the post-test were designed based on Lehrer's Data display construct. Each item in the tests was assigned to a certain level of the Data display construct. For instance the item that requires students to select an appropriate continuous scale was assigned to level DaD4A. The points given to each item depended on the level of the Data display assigned to it. Therefore an item at level DaD2B was given 1point, that at level DaD3A was given 1.5 points, at level DaD4A was given 2 points, and an item at level DaD5Awas given 3 points. Finally each level points were summed up in order to compare the students' results (see Appendix D for the total number of points assigned for each level).

Subsequent to pre-testing, implementing the unit, and post-testing, the three students were individually interviewed. In the interview each student was asked to compare and contrast the two teaching approaches (the traditional and IBMA). Moreover, they were asked to verify the new graphing skills that they developed after implementing the new approach.

Findings and expected benefits 
Comparing the tests' results showed that the students" graphing skills developed in various aspects. At level DaD2B of Lehrer's taxonomy, placing the given attributes on the right axis, two students scored high on both tests while the third student didn't know which the vertical axis is and which the horizontal axis is. At levels DaD3A (notice or construct groups of similar values from distinct values) and DaD4A (display data using continuous scale), the scores were significantly higher on the post-test than the pre-test. The highest score at DaD3A was $1.5 / 4.5$ (which is equivalent to $2.5 / 7.5$ ) on the pre-test; whereas on the post-test all students scored $7.5 / 7.5$ at this level. Selecting a continuous scale was the hardest task for those students. Their scores improved from $1 / 4$ on the pre-test to $4 / 4$ on the post-test. The scale they selected on the pre-test was missing appropriate units (meters and minutes) used and the right scale to be applied. The students improved notably on the task that required them to construct a line graph in order to find the missing data and then interpret it by recognizing that it provides information about data as a collective (DaDSA). On the pre-test the students were confused about the missing data where one of them suggested applying the cross-multiplication method, while another asked for a calculator. After unit implementation the students' scores at the DaD5A level increased from $0.5 / 3$ to $5.5 / 6$ (which is equivalent to $2.75 / 3$ ). In addition students improved in reading and selecting points on a line graph in the absence of numbers on the axes.

Based on the clinical interviews, the students had a preference for IBMA. Firstly they appreciated the process followed (Question, hypotheses, experiment, graph construction, and conclusion). Students were interested in approaching questions the way scientists do, one student stated "Now I know that scientists observe the environment in which they live, pose a question related to a certain problem, and then investigate it", another student commented "We can discover the topic". Secondly they mentioned that IBMA improved their graph construction and interpretation. The students stated the following: "We work on graphs at improved stages", "We 
can use graphs to find the accepted hypothesis", "I learned how to choose the right attributes and how to place them on the right axes", "I learned that graphs are not only used as extra activities, but they are also useful for inferring conclusions". Therefore students appreciated the value of this model, and were keen to improve their graphing skills by following this approach.

In order to achieve the optimum development in students' graphing skills, I recommend that more forms of graphs are included and implemented using IBMA. In this project the focus was on line graphs; however it would be also beneficial to focus on bar and pie graphs as well as histograms. Moreover it is also proposed to incorporate computer software for graph construction instead of using the paper-and-pencil method. In this case the mathematics teacher is invited to aid the approach by teaching students how to use the suitable software for this purpose. 


\section{THE UNIT PLAN}

The Original Unit in the Lebanese Curriculum

In an attempt to improve middle school students' graphing skills, the unit described here involves redesigning some of the lessons (each lesson's duration is I period) included in unit four of the grade 7 Lebanese biology textbook. This unit is entitled "Relations among the conditions of the environment, activity and functions of nutrition". The present unit involves redesigning the first five lessons of the original unit that aimed to attain the following objectives:

1. Notice that animal activity can be modified under the effect of environmental conditions.

2. Understand that the body temperature of poikilotherms is regulated by the external environment.

3. Understand that homiotherms always maintain a constant body temperature.

4. Relate the environmental temperature to body temperature of some animals.

5. Understand that when the environmental temperature decreases, poikilotherms decrease their activity.

6. Understand that when the environmental temperature decreases, the activity of the homiotherm remains constant.

7. Understand that the environmental temperature affects homiotherms' food and oxygen consumption.

8. Understand that the environmental temperature affects poikilotherms' food and oxygen consumption. 
The unit represents students with various documents such as pictures, graphs, and tabulated data, in addition to a "Glossary" section that defines new scientific words and a "Probing the activity" section that contains questions about the represented documents. For example, the first lesson entitled "Temperature and activity of an organism" starts with a general question "What is the influence of the external temperature on the internal temperature of animals and on their activity?" Then various documents are provided such as photos of animals, and tabulated data. In the "Probing the activity" section the questions focus on comparing and analyzing data, and constructing a graph starting with the tabulated data. The answers to the questions in this section are usually provided by the teacher with infrequent student involvement. Therefore, developing scientific skills such as investigating and interpreting data is mostly substituted by content teaching.

This unit is perceived as the suitable unit to be redesigned since it contains plenty of tabulated data that allows students to practice and deeply understand graphs. Moreover; the lessons' objectives are best attained when students work with and interpret graphs.

\section{Description of the Unit}

For the purpose of this project, five lessons are redesigned employing an inquiry-based modeling approach (IBMA) aiming to improve students' graphing skills. The objectives of the resulting five lessons are divided into "Graphing skills" objectives" and "Content objectives". The former are further divided based on the "Levels of Lehrer's data display construct" and "Other graphing skills" (see figure 1 for "Graphing skills' objectives" schema). The Data Display construct (see Appendix A) outlines the ways that students might approach constructing or interpreting a graph. It is divided into six levels starting at the level of a case-specific view of a display (DaD1A) and moving up towards an aggregate perspective of this display (DaD6A). 
Every lesson aims to develop students' graphing skills at a specific data display level. Each data display level includes certain objectives that have to be attained in the redesigned lessons. For instance, level DaD3A of the construct includes the objective "Notice the shape of the graph and point out any change in its appearance", and it is achieved in lesson 1. The "Other graphing skills" include skills that are not mentioned in the data display construct. The "Content objectives" (see figure 2 for the "Content objectives" schema) are largely similar to the content objectives provided by the original textbook, but they are formulated at higher levels of Bloom's taxonomy (analysis, application). The format of the activity is based on the different phases of the inquiry cycle. Phase 1 consists of raising a precise question and formulating its plausible hypotheses. In Phase 2 students investigate the question and structure data using data tables. This is accomplished either by deciding on the experiment's materials and procedure (without necessarily performing one) and then examining the given data, or by examining the data directly. Later in Phase 3 students represent and visualize data. In Phase 4 students interpret and draw conclusions from the data display. Finally in Phase 5 which is not applied in the redesigned lessons, students make further predictions. Throughout this cycle, students are expected to think about the given data and feel the need to construct line graphs in an attempt to reach an answer to the guiding question. Constructing and interpreting graphs play a major role in this cycle where students' work is guided by the information drawn from the graphical representations. Moreover, examining real life data will help students develop their graphing skills which will in turn help them construct their content knowledge.

This process is only successful with the guidance of a skilled teacher acting as a facilitator of the process. A skilled teacher's involvement is a fundamental requirement for the success of IBMA. In such an approach teachers are expected to motivate students' involvement by posing the main question of each lesson. The teacher has to make each question a real 
investigation and encourage students to think and work like scientists. Moreover, an expert teacher can guide learners' discussions by "Socratic" questioning (Jackson, Dukerich, \& Hestenes, 2008). In "Socratic" questioning answers are drawn out from pupils in order to test accuracy and completeness in students' thinking and to move them towards their ultimate goal. Throughout the discussion of the provided documents and data available, students will reach a stage where they sense the necessity of graph construction that will lead them towards the required conclusions. 


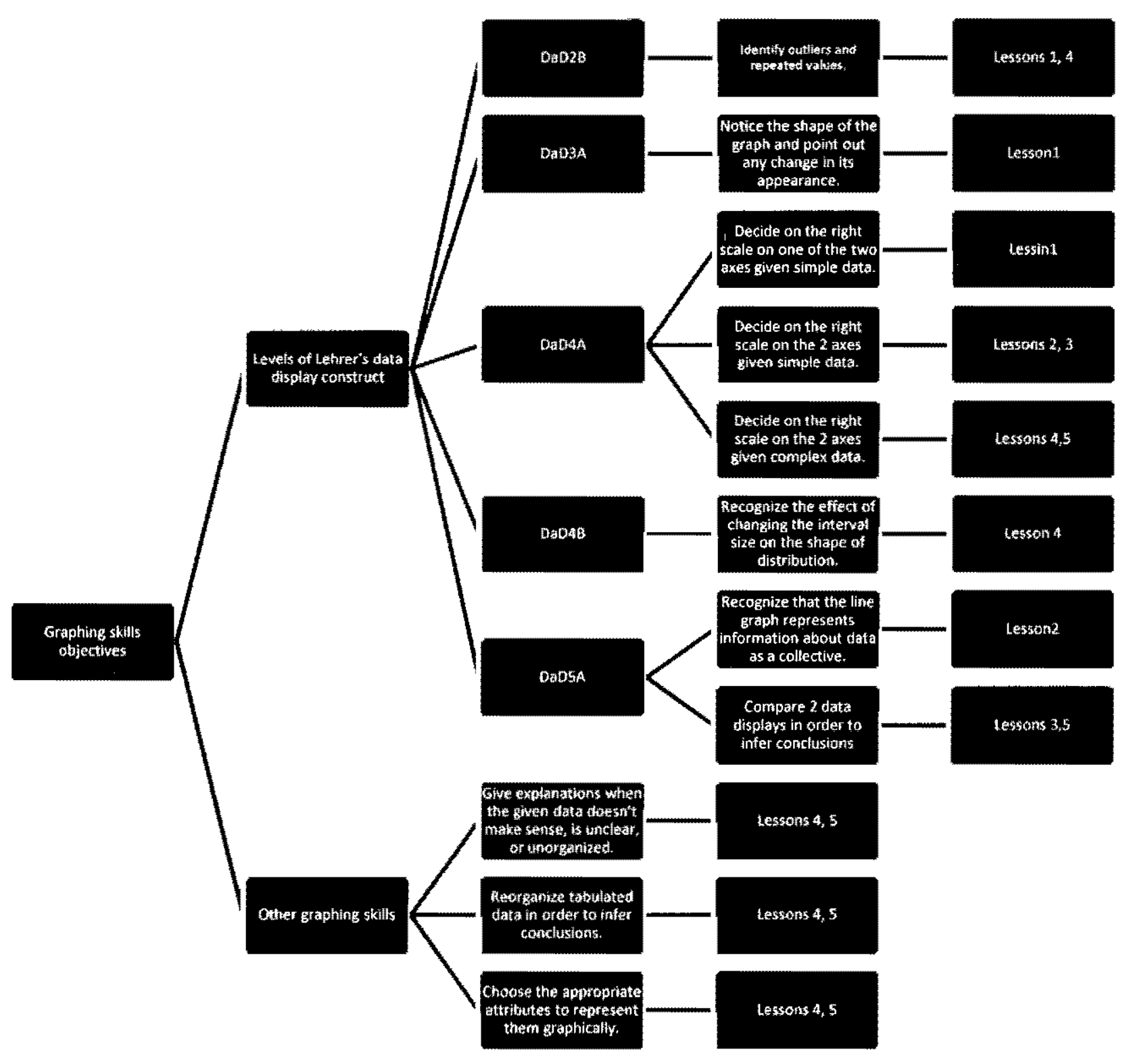

Figure 1. "Graphing skills' objectives" schema. This figure illustrates the organization of the graphing skills' objectives in the redesigned lessons, based on Lehrer's data display construct and on other graphing skills. 


\section{Content objectives}
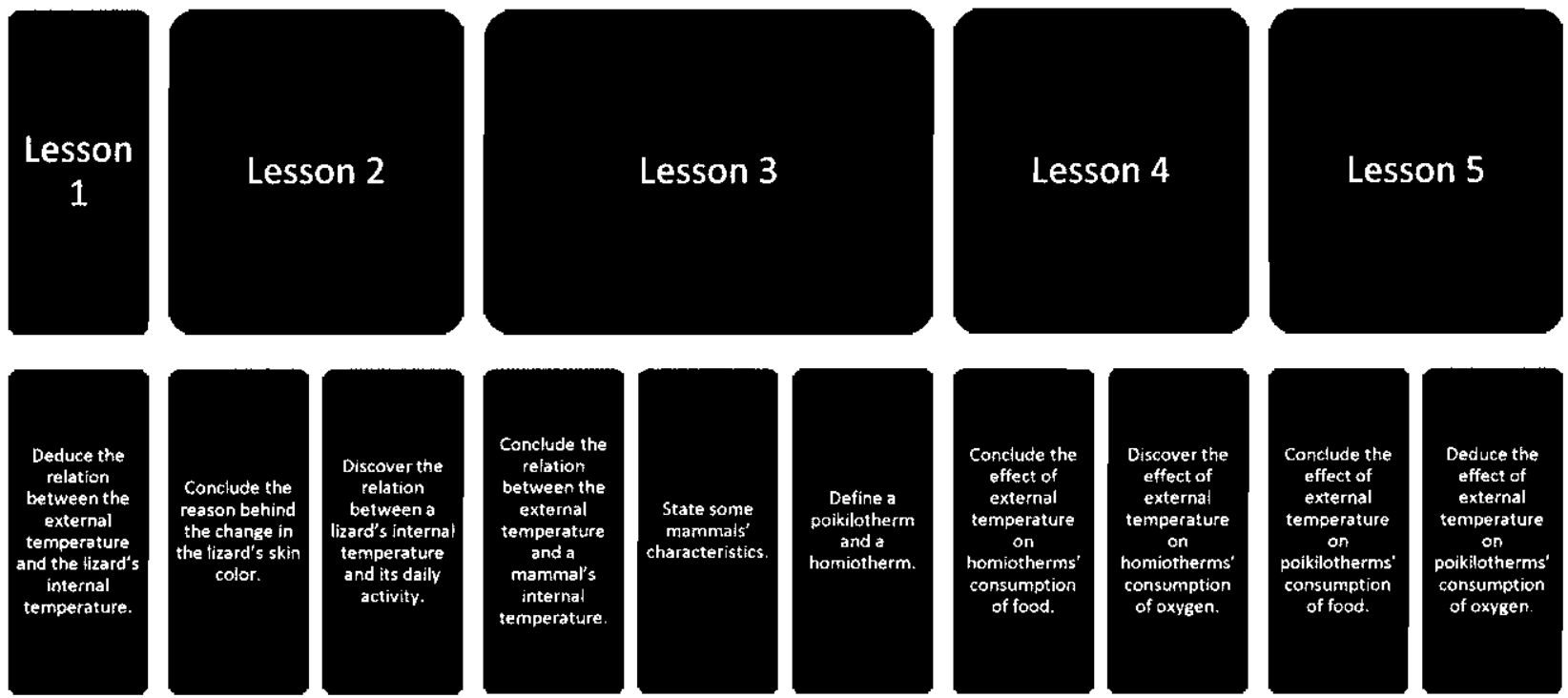

Figure 2. "Content objectives schema". This figure illustrates the content objectives in the redesigned lessons. 


\section{Unit Lesson Plans}

Lesson 1: The effect of the external temperature on the lizard's internal temperature

(Duration $=1 \mathrm{hr}$ )

Graphing skills' objectives: By the end of this session students will be able to:

- Construct a line graph starting with tabulated data.

- Identify outliers and repeated values (DaD2B).

- Notice the shape of the graph and point out any change in its appearance (Plateau) (DaD3A).

- Decide on the right scale on one of the two axes when given simple numbers (DaD4A).

Content objectives: By the end of this activity students will be able to :

- Deduce the relation between the external temperature and the lizard's internal temperature.

\section{Materials:}

- Students will be using: graph paper, copybook, pencil, calculator, and ruler.

- Teachers should have: the lesson's documents photocopied and given to students, an overhead projector to display the entire lesson's information written and organized (question, hypotheses, graphs), and graph paper transparencies.

\section{Procedure:}

- Phase 1: Start the session by telling the students that our work will be similar to the way scientists approach and solve problems. For this reason we will start by posing the Question: What is the effect of the external temperature on the lizard's internal temperature? 
Then ask students if they can think of any answers to the raised question. Emphasize that those answers are just personal predictions (Hypotheses) that can't be considered true or false; however after testing them they are either accepted or rejected.

Hypotheses: The lizard's internal temperature is not affected by the external temperature.

The lizard's internal temperature increases with an increase in the external temperature.

The lizard's internal temperature decreases with an increase in the external temperature.

- Phase 2: Then ask the students:

'Teacher: How can we find out which hypothesis to accept and which to reject? Student: Internet, or find it in the book.

Teacher: But we need to find an answer based on our work, we might want to discover something new that no one has investigated before.

Student: Then let's design an experiment.

Teacher: Can you think of the experiment's materials and design? To decide on those you have to go back to the main question, what are the keywords?

Student: External temperature, lizard's internal temperature.

Teacher: Can you now decide on the materials?

Student: We will use a thermometer to measure the external temperature, another one to measure the lizard's internal temperature, and a lizard.

$\checkmark$ Then the materials are:

1. Lizard

2. A thermometer to measure the external temperature.

3. A container to place the lizard in.

\footnotetext{
${ }^{1}$ Typical conversations that might take place between the teacher and the student. Those will be italicized and
} indented throughout the lesson plan. 
4. A thermometer to measure the lizard's internal temperature.

What about the procedure? (Listen to as much suggestions as possible from students)

Procedure:

How are we going to expose the lizard to different external temperatures in order to measure its internal temperature?

Place the lizard in the container in a sunny spot of the room where the external temperature is approximately $26^{\circ} \mathrm{C}$. Measure the lizard's internal temperature.

Repeat the same procedure when placing the lizard in a cold room with no sun light (e.g. setting the air conditioner) and with an external temperature of approximately $10^{\circ} \mathrm{C}$. Measure the lizard's internal temperature.

$\checkmark$ After measuring the lizard's internal temperature in the two different environmental conditions, what do we do next? Compare the lizard's body temperature in the two settings.

Teacher: What do you conclude?

Student: But we don't have the measurements to conclude

$\checkmark$ We are lucky that 2 scientists performed this experiment and each came up with a set of tabulated data represented in tables 1 and 2 .

Table 1

Periods of the day Lizard's internal temperature

in ${ }^{\circ} \mathrm{C}$

7-10 am 10-18

10-11 am 18-22

11-12 am 22-27

$12-13 \mathrm{pm} \quad 30-31$

$13-14 \mathrm{pm} \quad 31-33$

$14-15 \mathrm{pm} \quad 31-30$

$15-18 \mathrm{pm} \quad 30-18$

$18-19 \mathrm{pm} \quad 18-15$ 
Table 2

\begin{tabular}{lcc}
\hline Time of the day & $\begin{array}{c}\text { Extemal temperature in }{ }^{\circ} \mathrm{C} \\
\text { (izard's internal temperature } \\
\text { in }{ }^{\circ} \mathrm{C}\end{array}$ & $\begin{array}{c}\text { Lize } \\
8: 00 \mathrm{am}\end{array}$ \\
$9: 00 \mathrm{am}$ & 10 & 8 \\
$10: 00 \mathrm{am}$ & 15 & 17 \\
& 20 & 31 \\
$1: 00 \mathrm{pm}$ & 25 & 33 \\
& 30 & 33 \\
\hline
\end{tabular}

Examine tables 1 and 2:

Teacher: What information does table 1 represent?

Student: Periods of the day and the lizard's internal temperature, the changes in the lizard's internal temperature according to a certain period of the day

Teacher: What information does table 2 represent?

Student: The variation of the lizard's internal temperature as the external temperature change according to a specific time of the day.

Teacher: What is the question stated at the beginning of this session and we are trying to answer?

Student: What is the effect of the external temperature on the lizard's internal temperature?

Teacher: Which table will help us answer this question I or 2? Why?

Student: Table 2, since it contains both internal and external temperatures.

Examine table 2:

Teacher: What's wrong with this document?

Student: it's missing some data

$\checkmark$ On a typical Lebanese summer day complete the missing data in the first column of the table. (When is the temperature $5^{\circ} \mathrm{C}$ on a summer day? $25^{\circ} \mathrm{C} ? 32^{\circ} \mathrm{C}$ )

$\checkmark$ How can we find the missing internal temperatures?

Student: Compute, cross multiplication, guess, perform the experiment, we don't need the missing temperatures, we might represent the data graphically... this conversation should lead students to decide on constructing a line graph which is the only way to find the missing data.

What attributes (Information that will be represented on the axes) does constructing the graph require (Encourage them to find attributes through the main question)? 


\section{Student: external temperature and internal temperature.}

$\checkmark$ If $y$ changes as a function of $\mathrm{x}$, then on which axis will you place the external temperature? The internal temperature? (Encourage the students to read the main question again in order to decide on which of the two attributes is affecting the other.)

$\checkmark$ What is the scale that you will use for this graph given that the scale on the $\mathrm{x}$-axis is $5^{\circ} \mathrm{C}=$ 1 unit? (Listen to students suggestions and always ask "Why did you choose this scale?" "How much is each interval?" "Are you considering equal intervals?"(Most appropriate scale: $\mathrm{x}$-axis $5^{\circ} \mathrm{C}=1$ unit, $\mathrm{y}$-axis $5^{\circ} \mathrm{C}=1$ unit).

- Phase 3: Construct the graph. (Figure 3 is the solution).

\section{Series 1}

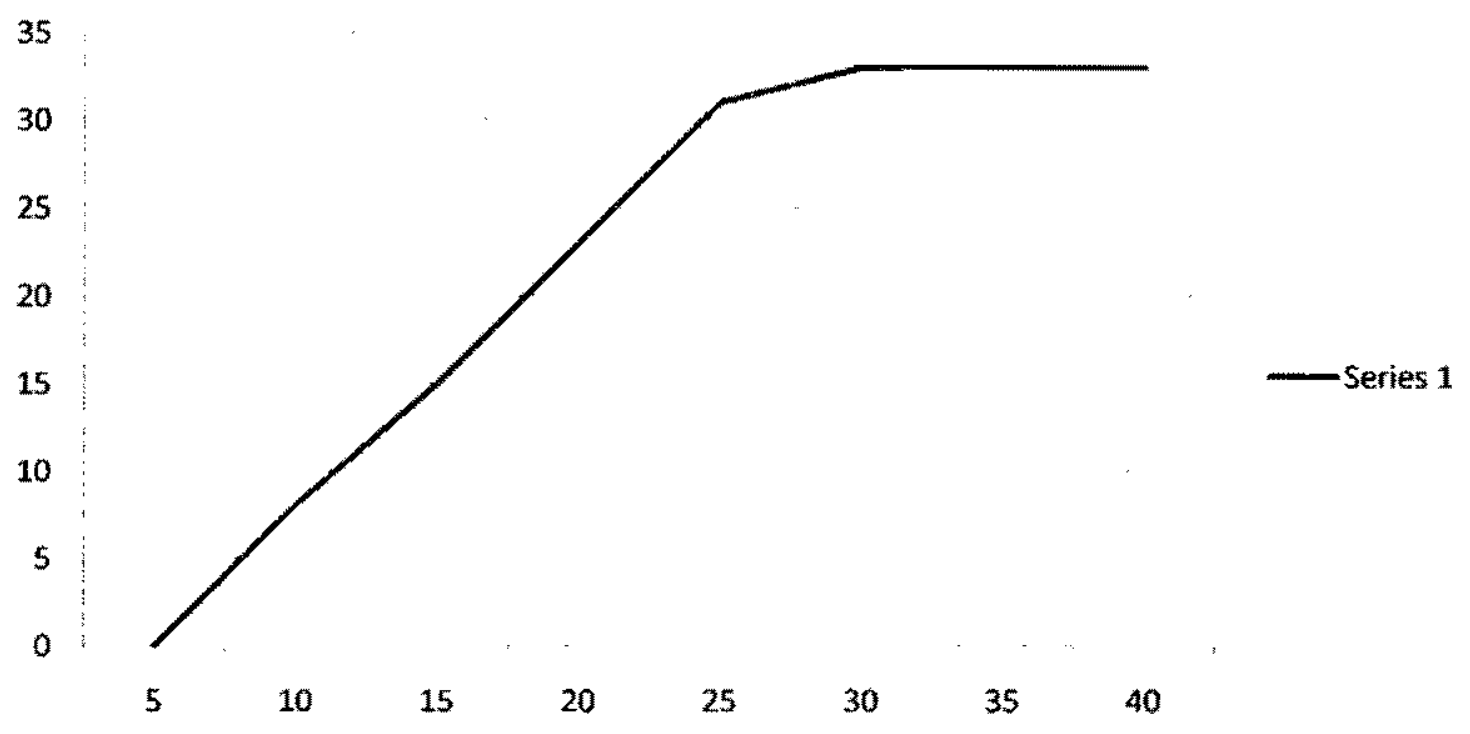

Figure 3.

When students start joining the points on the graph, ask them if they would prefer to remove any point in order to get a better graphical appearance, when they realize that they can drop point 15 on $\mathrm{x}$-axis inform them that such points are called outliers and it is acceptable to drop them. 
Teacher: After constructing the graph, what do you notice about its shape as the external temperature is $30^{\circ} \mathrm{C}$ and above?

Student: The shape has changed to a straight horizontal line.

Teacher: This is what we call a plateau.

- Phase 4: Based on the obtained graph, complete the missing information in table 2. The students are encouraged to use their rulers in order to find the missing data. (Table 3 is the solution)

\begin{tabular}{cc} 
Table 3 & \\
\hline External temperature & Internal temperature \\
5 & 1 \\
20 & 23 \\
32 & 33 \\
\hline
\end{tabular}

$\checkmark$ Based on this graph, can you now decide on which hypothesis to accept out of the 3 hypotheses represented at the beginning of this session? (The second hypothesis is accepted, while the others are rejected)

\section{- Assignment:}

1. Do you think that one can realize the change in the lizard's internal temperature by looking at it? How? (Find your answer by asking someone in your surrounding you think might have the answer, by searching the web, or by observing a lizard if available.)

2. Do you think that the variation in the lizard's internal temperature affects its daily activity? 
Lesson 2: Changes in the lizard's skin color and daily activity. (Duration=1hr)

Graphing skills' objectives: By the end of this session students will be able to:

- Construct a line graph starting with tabulated data.

- Decide on the right scale on the two axes when given simple numbers (DaD4A).

- Recognize that the line graph represents information about data as a collective. (DaD5A)

Content objectives: By the end of this activity students will be able to :

- Conclude the reason behind the change in the lizard's skin color.

- Discover the relation between a lizard's internal temperature and its daily activity.

\section{Materials:}

- Students will be using: graph paper, copybook, pencil, calculator, and ruler.

- Teachers should have: the lesson's documents photocopied and given to students, an overhead projector to display the entire lesson's information written and organized (question, hypotheses, graphs), and graph paper transparencies.

\section{Procedure:}

- Start the session by listening to students answers to the assignment questions. Then inform them that the class altogether will be investigating the questions.

Part1: In order to find an answer to the first question concerning the lizard's skin color, doc.c is represented to us by a scientist who was interested in observing animals' behaviors: 


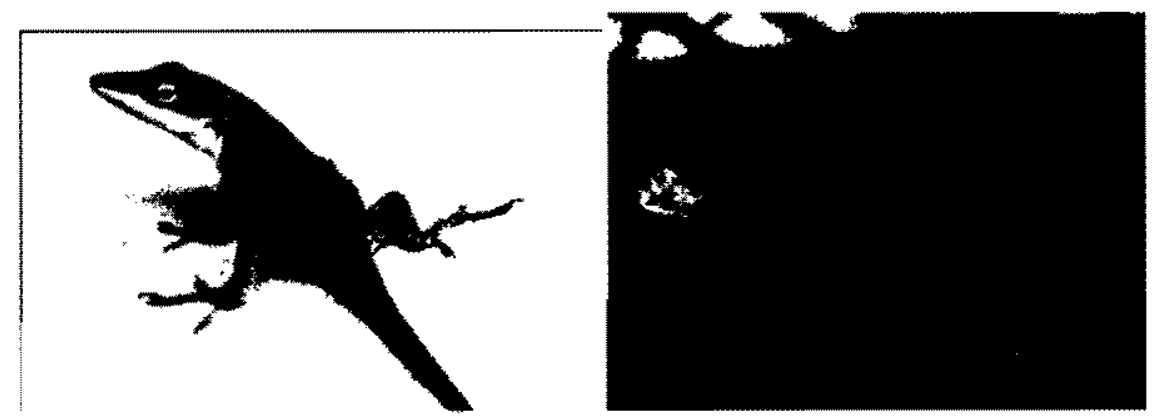

Figure 4.

Observe figure 4, what do you notice?

Student: The lizard changes its color in different conditions.

Teacher: With different external conditions the lizard appears to have different skin colors. Why is that?

Encourage the students to think about the color of clothes people usually choose to wear in summer and those they choose in winter, do you prefer to wear dark colors in winter or in summer? Why? (Dark colors capture more heat than light colors, that's why in sunlight the lizard's skin color is light to prevent it from capturing heat and from an additional increase in its internal temperature. However in shade the lizard's skin color changes into a dark one that helps it capture more heat which in turn leads to an increase in its internal temperature).

Part2: The investigation that we will perform in this part will help us answer the second question of your assignment:

- Phase1: The question is: Does the variation in the lizard's internal temperature affect its daily activity?

The students should state those hypotheses:

The lizard's internal temperature affects its daily activity.

The lizard's internal temperature has nothing to do with its activity.

- Phase 2: I have found the following data (table 4)produced by a scientist who investigated the same question. 
Table 4

$\begin{array}{cc}\text { External temperature in }{ }^{\circ} \mathrm{C} & \begin{array}{c}\text { Lizard's activity in } \mathrm{AU} \\ \text { (Activity Unit) }\end{array} \\ 20 & 80 \\ 32 & 75 \\ 5 & 0\end{array}$

Examine table 4:

Teacher: What does this table represent?

Student: The external temperature in ${ }^{\circ} \mathrm{C}$ and the animal's activity in $A U$.

Teacher: Does the variation in the external temperature affect the lizard's daily activity? How?

Student: Yes, as the external temperature changes the animal's activity changes.

- Phase 3: Refer to the missing information found in table 4 to construct a graph representing the effect of the lizard's internal temperature on its activity. (Students should first reproduce the table then construct the graph. At this stage students should know that they have first to decide on the scale and the attributes without telling them). (Table 5 and figure 5 are the solution)

Table 5

\begin{tabular}{lcc}
\hline External temperature in ${ }^{\circ} \mathrm{C}$ & $\begin{array}{c}\text { Lizard's internal } \\
\text { temperature in }{ }^{\circ} \mathrm{C}\end{array}$ & $\begin{array}{c}\text { Lizard's activity in AU } \\
\text { (Activity Unit) }\end{array}$ \\
20 & 23 & 80 \\
32 & 33 & 75 \\
5 & 1 & 0 \\
\hline
\end{tabular}




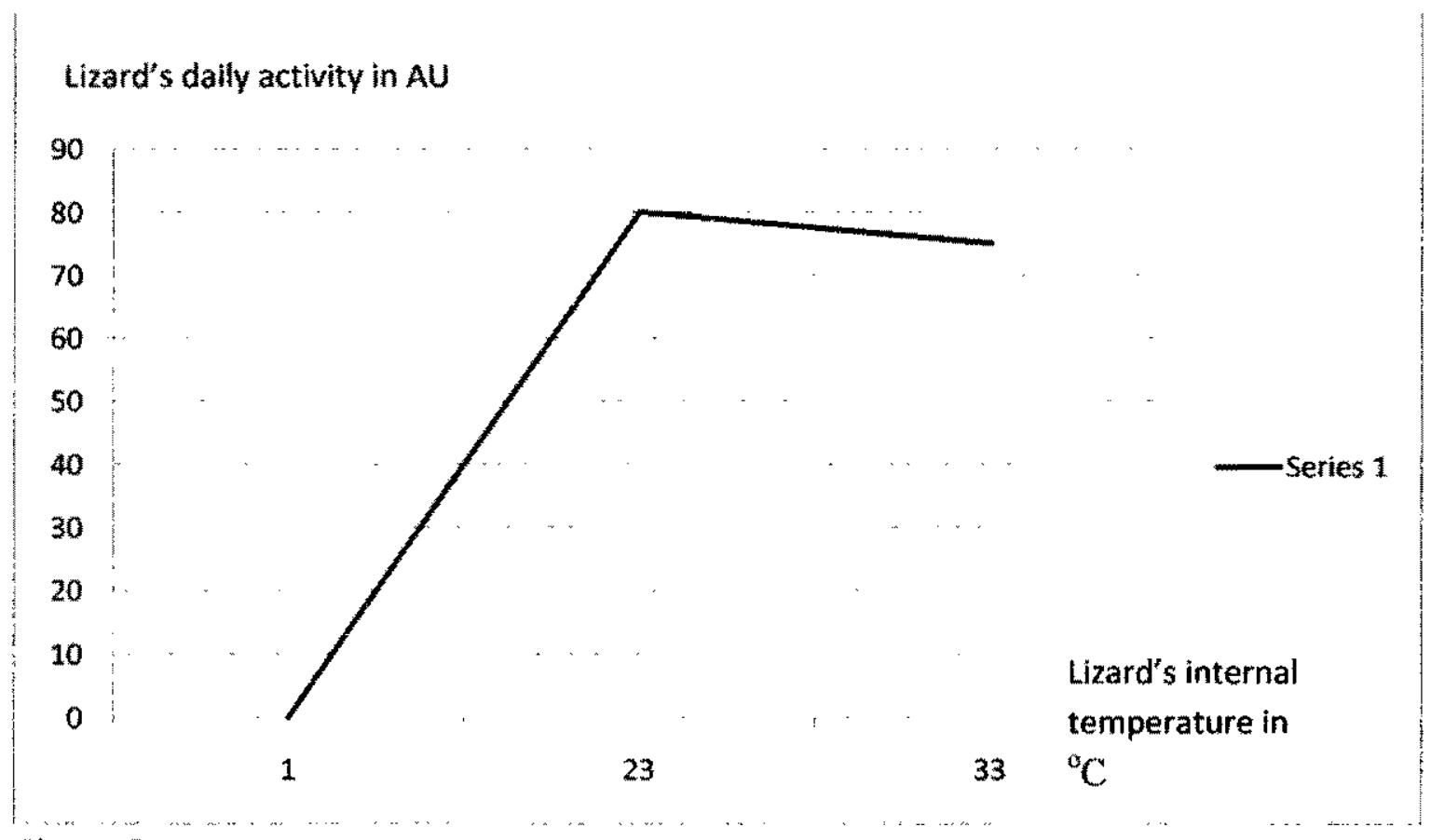

Figure 5.

- Phase 4:

Teacher: after reproducing the table and constructing the line graph, which hypothesis will you accept?

Student: The lizard's internal temperature affects its daily activity.

\section{- Assignment:}

We have studied the effect of the external temperature on one animal's internal temperature which is a lizard, what would be the relation between the internal temperature and the external temperature if the animal is: a horse, a cat, a dog, a mouse? 
Lesson 3: The effect of the external temperature on homiotherm's internal temperature.

(Duration $=1 \mathrm{hr}$ )

(In this lesson Phases 2 and 3 are combined since students are not asked to construct a graph, but to draw information from a given one)

Graphing skills' objectives: By the end of this session students will be able to:

- Decide on the right scale on the two axes when given simple numbers (DaD4A).

- Compare two data displays in order to infer conclusions (DaD5A)

Content objectives: By the end of this activity students will be able to:

- State some mammals' characteristics.

- Conclude the relation between the external temperature and a mammal's internal temperature.

- Define a poikilotherm and a homiotherm.

\section{Materials:}

- Students will be using: graph paper, copybook, pencil, calculator, and ruler.

- Teachers should have: the lesson's documents photocopied and given to students, an overhead projector to display the entire lesson's information written and organized (question, hypotheses, graphs), and graph paper transparencies.

\section{Procedure:}

- Phase 1: Now we know how the lizard's internal temperature varies as a function of the external temperature.

Teacher: Let's examine the relationship between the external temperature and the internal temperature of animal $x$ in order to know its type. So what do we have to state first?

Student: The question.

Teacher: What would be a suitable question for this investigation?

Student: What is the type of animal $x$ based on the relation between the external temperature and its internal temperature?

Teacher: Formulate the hypotheses. 


\section{Student: Animal $x$ is a lizard.}

Animal $x$ is a different type of animal.

- Phases 2 and 3: Figure 6 shows the graphical representation provided by a scientist who studied the effect of the external temperature on animal $x$ internal temperature. Examine figure 6:

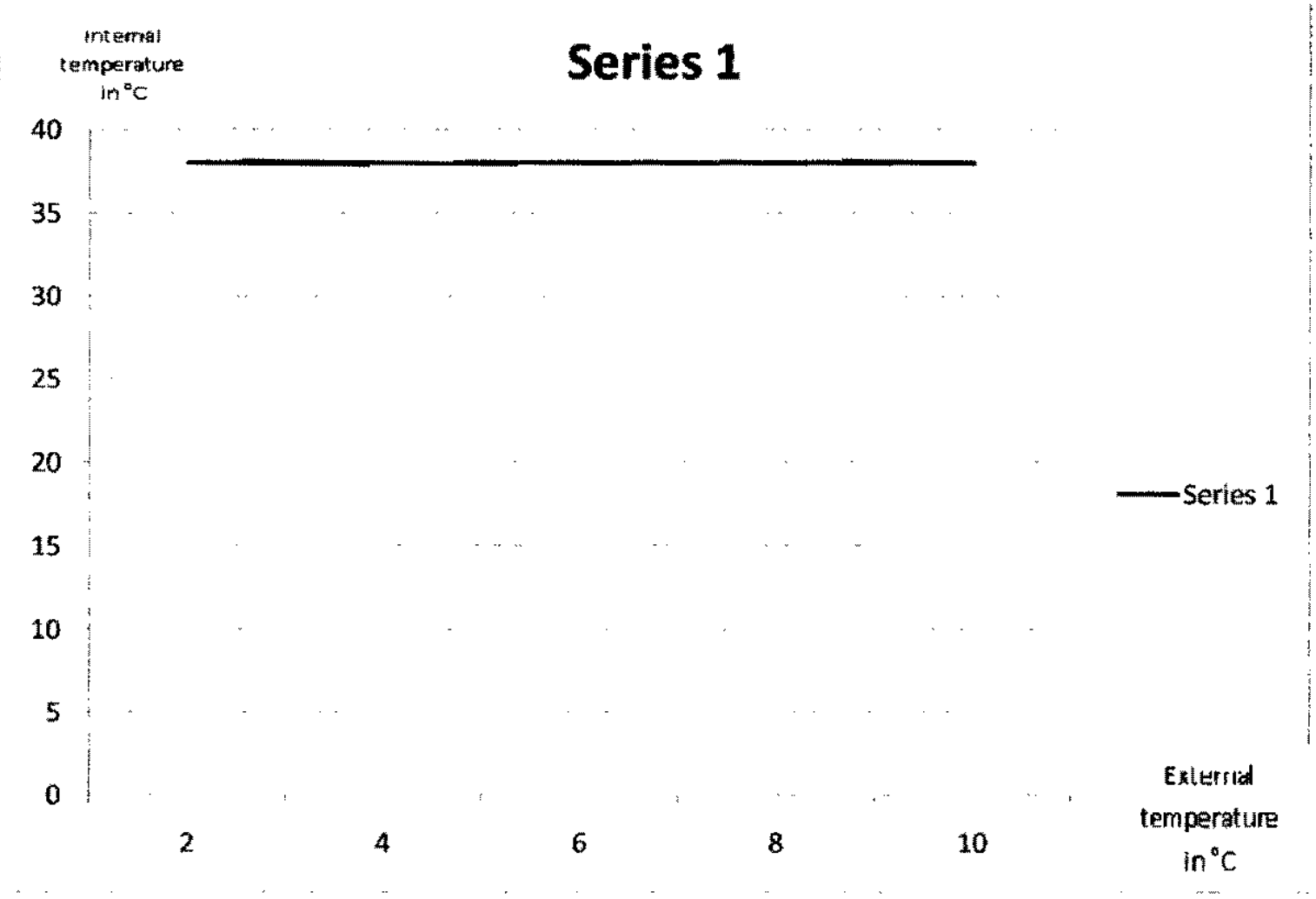

Figure 6.

$\checkmark$ What is the scale used? Is there any other possible scale that can be used in this display? (The scale: $x$-axis: lunit $=2^{\circ} \mathrm{C}$, y-axis: 1 unit $=5^{\circ} \mathrm{C}$ )

$\checkmark$ Compare the above graph to the one you constructed for studying the relation between the external temperature and the lizard's internal temperature.

$\checkmark$ Was this scientist experimenting on a lizard?

$\checkmark$ If no, think of your own internal temperature and its variation with the external temperature, is it similar to what's represented in the above graph? (Whatever the external temperature is, 
human's internal temperature is always stable at $37^{\circ} \mathrm{C}$ unless there's a certain infection which leads to an increase in the internal temperature).

Teacher: But we know that this scientist studies only animals, therefore this is an animal that has an internal-external temperature relation similar to humans. Can you think of some characteristics that might help us find out what animal was the scientist studying?

Student: it has to have a suitable size to fit in the container, harmless, and like humans.

Teacher: Do you know that humans are mammals? What are some mammals' characteristics? warm-blooded (their internal temperature is not affected by the variation in the external temperature), most have lungs and breathe in air= except whales and dolphins, most of them give birth rather than laying eggs, most give milk, and walk on four legs. The whale is the largest mammal and the shrew is the smallest one).

- Phase 4: So if we are considering a suitable animal to fit the graphical representation, then it has to be as stated previously by students:

\section{Harmless}

2. It has to fit in the container= lizard's size

3. Warm-blooded

4. It has to have hair

5. It has to have lungs and breathe in air.

Therefore this animal might be a mouse, vole, guinea pig... That is this animal is not a lizard it's a mammal.

$\checkmark$ Decide on a label (poikilotherms or homiotherms) for animals with constant internal temperature and one which is dependent on the external temperature, knowing that poikilo is a Greek word meaning varied? Label animals with a variable internal body temperature. 
- Assignment:

Now you know the relation between the external temperature and different animals' internal temperature, for next time think about how the external temperature might affect those animals' food consumption. 
Lesson 4: The effect of the external temperature on homiotherms' food and oxygen consumption. (Duration $=1 \mathrm{hr}$ )

Graphing skills' objectives: By the end of this session students will be able to:

- Give explanations when the given data doesn't make sense, is unclear, or unorganized.

- Reorganize tabulated data in order to infer conclusions.

- Construct a graph starting with complex data (Decimal numbers).

- Display data by using continuous scale when dealing with complex data (decimal numbers) (DaD4A).

- Recognize the effect of changing the interval size on the shape of distribution (DaD4B).

- Choose the appropriate attributes to represent them graphically.

- Identify outliers and repeated values (DaD2B).

Content objectives: By the end of this activity students will be able to :

- Conclude the effect of external temperature on homiotherms' consumption of food.

- Discover the effect of external temperature on homiotherms' consumption oxygen.

\section{Materials:}

- Students will be using: graph paper, copybook, pencil, calculator, and ruler.

- Teachers should have: the lesson's documents photocopied and given to students, an overhead projector to display the entire lesson's information written and organized (question, hypotheses, graphs), and graph paper transparencies.

\section{Procedure:}

- Phase 1: Question: How do food and oxygen consumptions vary with the external temperature variation in animal 1 ? 
Hypotheses: 1 . Both increase with an increase in the external temperature.

2. Both decrease with an increase in the external temperature.

3. Both are independent of the external temperature.

4. Oxygen consumption increases while food consumption decreases with an increase in the external temperature.

5. Oxygen consumption decreases while food consumption increases with an increase in the external temperature.

Phase 2: An experiment was performed to find an answer to the above question. This experiment yielded the following table in table 6 :

\begin{tabular}{lcccc}
$\begin{array}{l}\text { Table 6 } \\
\text { Days of the } \\
\text { week }\end{array}$ & $\begin{array}{c}\text { External } \\
\text { temperature in } \\
{ }^{\circ} \mathrm{C}\end{array}$ & $\begin{array}{c}\text { Internal } \\
\text { temperature } \\
\text { i }{ }^{\circ} \mathrm{C}\end{array}$ & $\begin{array}{c}\text { Food } \\
\text { consumption } \\
\text { in grams }\end{array}$ & $\begin{array}{c}\text { Oxygen } \\
\text { consumption } \\
\text { in ml/min }\end{array}$ \\
Friday & 20 & 38 & 4.4 & 6.5 \\
Thursday & 17 & 38 & 4.8 & 6 \\
Monday & 4 & 38 & 6.5 & 15 \\
Tuesday & 5 & 38 & 6.5 & 14 \\
Sunday & 6 & 38 & 5.4 & 12.5 \\
Wednesday & 5.5 & 38 & 6.3 & 13 \\
Saturday & 18 & 38 & 4.7 & 6 \\
\hline
\end{tabular}

Teacher: First of all can you tell what is the type of animal 1 ? What attributes did you depend on to answer?

Student: after looking at the internal and external temperatures: Animall is a homiotherm, warm-blooded, vole, mammals.

Teacher: Look at the first two columns; does the given data make sense? Is it possible to have a very low temperature on one day and a much higher one on the following day? So what do you suggest is wrong with this data?

Student: something was wrong with the thermometer while measuring the external temperature; maybe the data are not taken in the same week.

$\checkmark$ Considering this animal's food consumption, does it vary with a variation in the external temperature? How?

$\checkmark$ It varies but it's really hard to figure it out with this unorganized data. Therefore: 
Teacher: What are the attributes required to represent data graphically and to be able to answer the main question?

Student: food consumption on $y$-axis and external temperature on $x$-axis.

- Phase 3: Reorganize table 6 data in a separate two-column table and construct the graph.

(Table 7 and figure 7 are the solution)

\begin{tabular}{cc} 
Table 7 & \\
\hline External temperature in ${ }^{\circ} \mathrm{C}$ & Food consumption in grams \\
4 & 6.5 \\
5 & 6.5 \\
5.5 & 6.3 \\
6 & 5.4 \\
17 & 4.8 \\
18 & 4.7 \\
20 & 4.4 \\
\hline
\end{tabular}

Food consumption in

grams

- External temperature in ${ }^{\circ} \mathrm{C}$

Figure 7.

- Phase 4:

$\checkmark$ Identify the outliers that appear in this display. $(6,5.5)$

$\checkmark$ Conclusion: the variation in the external temperature affects this animal's food consumption that is as the external temperature increases this animal's food consumption decreases.

- For this section reproduce phases 2,3 and 4 again but this time for oxygen consumption. What can you say about oxygen consumption of this animal as a function of 
the external temperature? At this stage students have to figure out that they must reorganize tabulated data, construct a graph and the draw conclusions. (Table 8 and figure 8 are the solution)

\begin{tabular}{cc} 
Table 8 & \\
\hline $\begin{array}{c}\text { External } \\
\text { temperature } \\
\text { in }{ }^{\circ} \mathrm{C}\end{array}$ & $\begin{array}{c}\text { Oxygen } \\
\text { consumption } \\
\text { in ml/min }\end{array}$ \\
5 & 15 \\
5 & 14 \\
5.5 & 13 \\
6 & 12.5 \\
17 & 6 \\
18 & 6 \\
20 & 6.5 \\
\hline
\end{tabular}

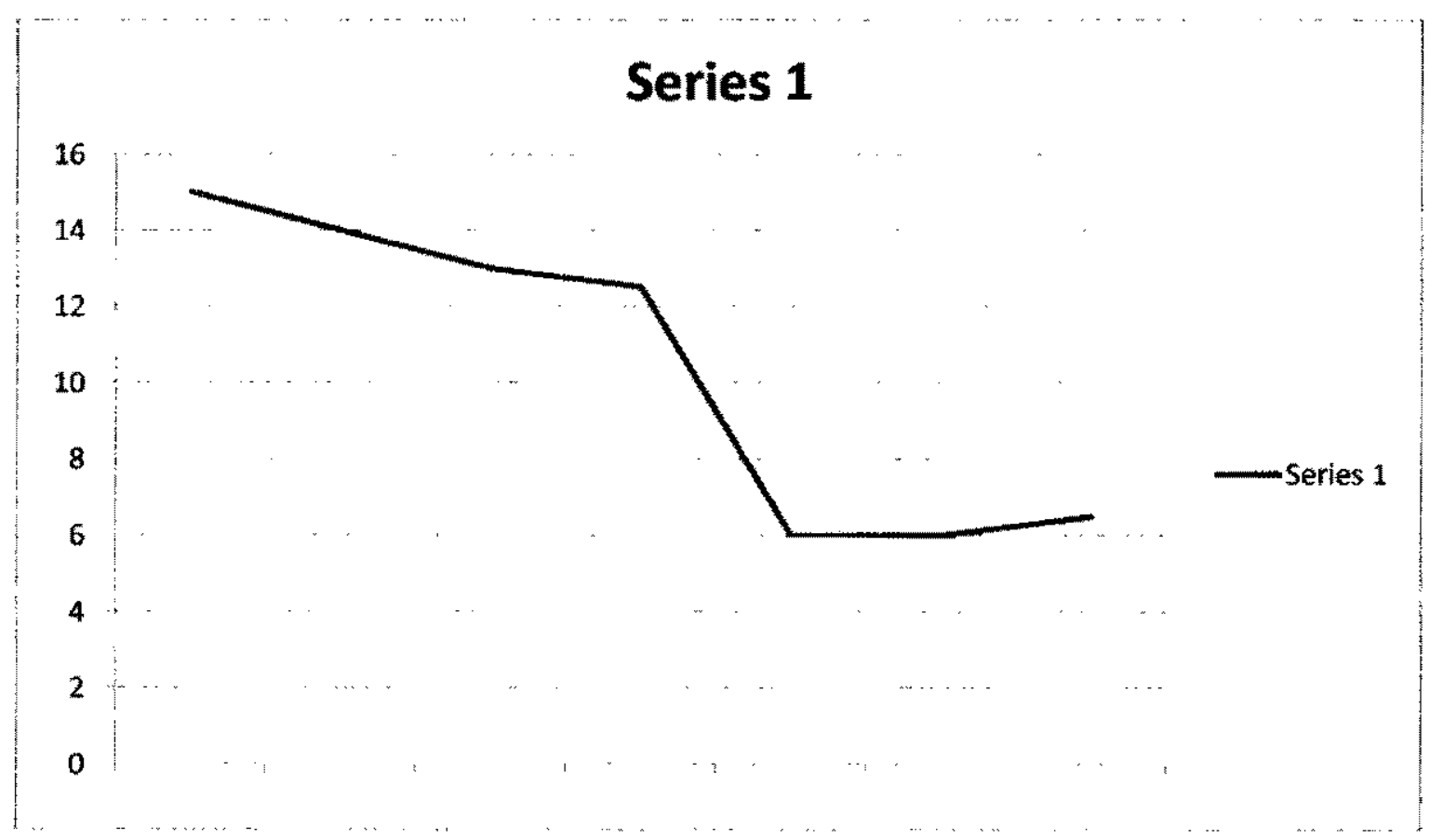

Figure 8 .

Teacher: Based on the constructed graph, which hypothesis will you accept? Student: Both decrease with an increase in the external temperature.

- Assignment

Revise lesson 4 
Lesson 5: The effect of the external temperature on poikilotherms' food and oxygen consumption. (Duration $=1 \mathrm{hr}$ )

Graphing skills' objectives: By the end of this session students will be able to:

- Give explanations when the given data doesn't make sense, is unclear, or unorganized.

- Reorganize tabulated data in order to infer conclusions.

- Construct a graph starting with complex data (Decimal numbers).

- Display data by using continuous scale when dealing with complex data (DaD4A).

- Choose the appropriate attributes to represent them graphically.

- Compare two data displays in order to infer conclusions (DaD5A).

Content objectives: By the end of this activity students will be able to :

- Conclude the effect of external temperature on poikilotherms' consumption of food.

- Deduce the effect of external temperature on poikilotherms' consumption oxygen.

\section{Materials:}

- Students will be using: graph paper, copybook, pencil, calculator, and ruler.

- Teachers should have: the lesson's documents photocopied and given to students, an overhead projector to display the entire lesson's information written and organized (question, hypotheses, graphs), and graph paper transparencies.

\section{Procedure:}

- Phase 1: Question: How do food and oxygen consumptions vary with the external temperature variation in animal 2 ?

Hypotheses: 1. Both increase with an increase in the external temperature.

2. Both decrease with an increase in the external temperature. 
3. Both are independent on the external temperature.

4. Oxygen consumption increases while food consumption decreases with an increase in the external temperature.

5. Oxygen consumption decreases while food consumption increases with an increase in the external temperature.

- Phase 2: Let's design an experiment to measure an animal's food consumption:

Materials: an animal (lizard or mouse), food, scale to measure grams of food, thermometer to measure external temperature.

$\checkmark$ Procedure: set the external temperature at $10^{\circ} \mathrm{C}$ and provide the animal with $1 \mathrm{~g}$ of food. After $3 \mathrm{hrs}$ measure the amount of food left and calculate the amount of food eaten (1g - amount left= amount eaten). Repeat the same procedure after setting the external temperature at $30^{\circ} \mathrm{C}$.

Do you think the amounts that we will get at 2 different temperatures will be different?

- Phases 3 and 4: A scientist who performed a similar experiment on animal 2 produced the data in table 9:

\begin{tabular}{lccc} 
Table 9 & & & \\
\hline $\begin{array}{l}\text { Days of the } \\
\text { week }\end{array}$ & $\begin{array}{c}\text { External } \\
\text { temperature } \\
\text { in }{ }^{\circ} \mathrm{C}\end{array}$ & $\begin{array}{c}\text { Internal } \\
\text { temperature } \\
\text { in }{ }^{\circ} \mathrm{C}\end{array}$ & $\begin{array}{c}\text { Food } \\
\text { consumption } \\
\text { in grams }\end{array}$ \\
1 & 20 & 18 & \\
2 & 17 & 17.4 & \\
3 & 4 & 4.9 & \\
4 & 5 & 5 & \\
5 & 6 & 5.2 & \\
6 & 5.5 & 5 & \\
7 & 18 & 17.8 & \\
\hline
\end{tabular}

Teacher: Is animal 2 a poikilotherm or a homiotherm?

Student: after looking at the internal and external temperatures, this animal is a poikilotherm. 
$\checkmark$ This scientist seemed to forget inserting the food consumption data, but he did provide us with the following data displays in figures 9 and 10 :

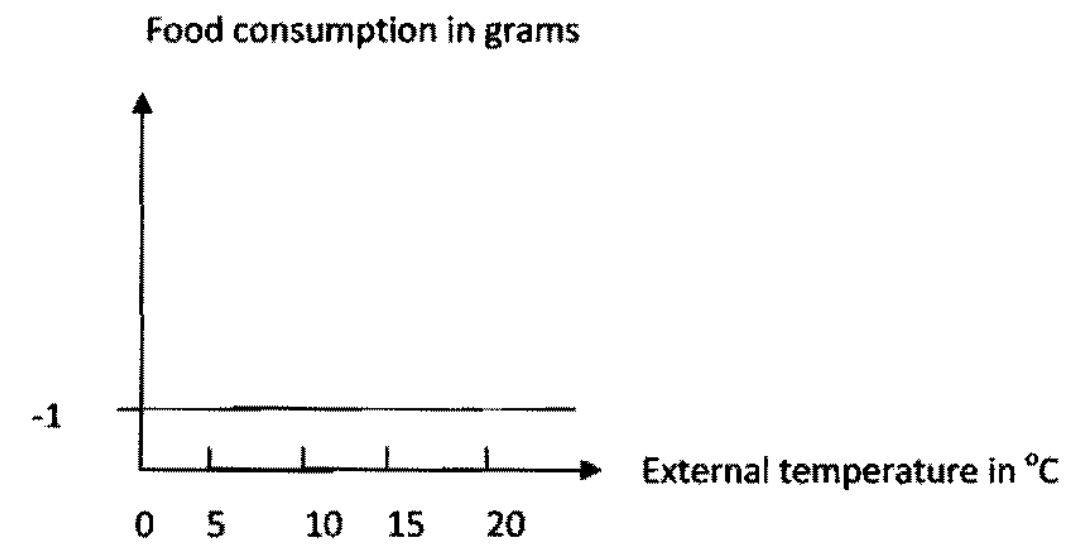

Figure 9

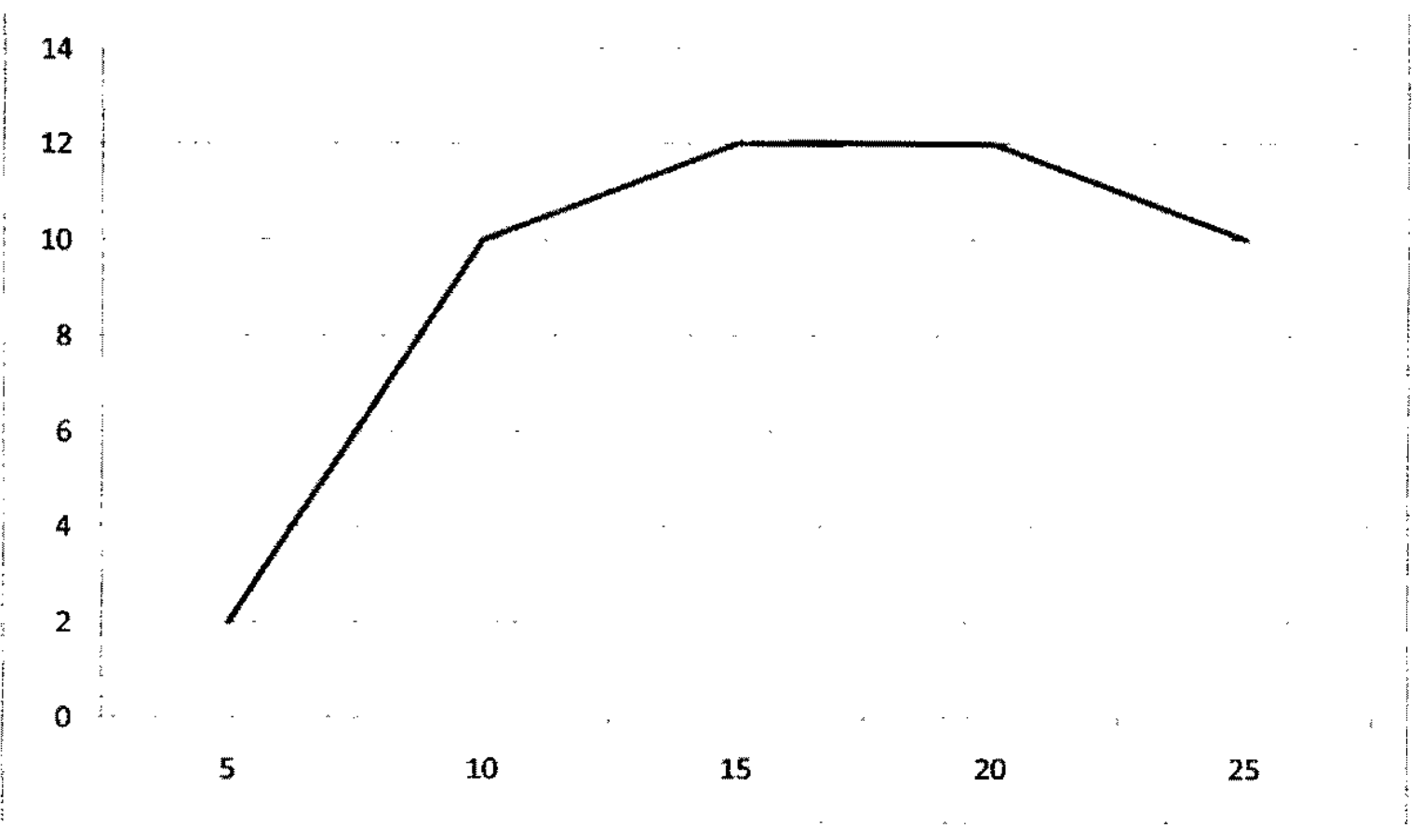

Figure 10. 
Teacher: Examine figure 9; is there anything wrong about it? (Scale, relation between external temperature and food consumption), is this the right display of the missing data?

Student: this is not the right display since -1 is placed above 0

Teacher: Examine figure 10; is there anything wrong or missing? (Scale, $x$-axis and $y$-axis titles, relation between the axes), is this the right display of the missing data? If yes add what's missing to make it clearer.

Student: the scale is right and the shape seems right too, we have to add the attributes: external temperature $(\mathrm{C})$ on $x$-axis and food consumption (g) on $y$ axis.

Based on the figure that you chose, reorganize and fill in the missing data in table 9. (Table 10 is the solution)

\begin{tabular}{cc} 
Table 10 & \\
\hline $\begin{array}{c}\text { External } \\
\text { temperature }\end{array}$ & $\begin{array}{c}\text { Food } \\
\text { consumption }\end{array}$ \\
in ${ }^{\circ} \mathrm{C}$ & in grams \\
4 & 1.8 \\
5 & 2 \\
5.5 & 2.2 \\
6 & 4 \\
17 & 12 \\
18 & 12 \\
20 & 12 \\
\hline
\end{tabular}

- For this section reproduce phases 2,3 and 4 again but this time for oxygen consumption. What about oxygen consumption, do you think that the variation of oxygen consumption as a function of external temperature is similar to that of food consumption?

- Phase 2: Examine table 11:

Table 11

\begin{tabular}{lccc}
\hline $\begin{array}{l}\text { Days of the } \\
\text { week }\end{array}$ & $\begin{array}{c}\text { External } \\
\text { temperature } \\
\text { in }{ }^{\circ} \mathrm{C}\end{array}$ & $\begin{array}{c}\text { Internal } \\
\text { temperature } \\
\text { in }{ }^{\circ} \mathrm{C}\end{array}$ & $\begin{array}{c}\text { Oxygen } \\
\text { consumption } \\
\text { in } \mathrm{ml} / \mathrm{min}\end{array}$ \\
1 & 20 & 18 & 3.8 \\
2 & 17 & 17.4 & 4 \\
3 & 4 & 4.9 & 1.2 \\
4 & 5 & 5 & 1.1 \\
5 & 6 & 5.2 & 1.1 \\
6 & 5.5 & 5 & 1.1 \\
7 & 18 & 17.8 & 3.7 \\
\hline
\end{tabular}


- Phase 3: Students have to decide on reorganizing the table and then constructing the graph.

(Table 12 and figure 11 are the solution)

\begin{tabular}{cc} 
Table 12 & \\
\hline $\begin{array}{c}\text { External } \\
\text { temperature } \\
\text { in }{ }^{\circ} \mathrm{C}\end{array}$ & $\begin{array}{c}\text { Oxygen } \\
\text { consumption } \\
\text { in ml/min }\end{array}$ \\
5 & 1.2 \\
5 & 1.1 \\
5.5 & 1.1 \\
6 & 1.1 \\
17 & 4 \\
18 & 3.7 \\
20 & 3.8 \\
\hline
\end{tabular}

\section{Series 1}

$$
\begin{array}{|r|}
4.5 \\
4 \\
3.5 \\
3 \\
2.5 \\
2 \\
1.5 \\
1 \\
0.5 \\
0
\end{array}
$$

Figure 11

- Phase 4: The accepted hypothesis is 1: Both increase as the external temperature increases. 


\section{References}

Anderson, R. (2007). Inquiry as an organizing theme for science curricula. In S. Abell \& N. Lederman (Eds.), Handbook of Research in Science Education (pp. 807-821). Mahwah, NJ: Erlbaum.

Boujaoude, S. (2002). Balance of scientific literacy themes in science curricula: The case of Lebanon. International Journal Science Education, 24(2), 139-156.

BouJaoude, S. (2007). Enhancing Students' Ability to Learn Meaningfully in Science. Melange: Revue Culturelle du Secrétariat General des Ecoles Catholique aux Liban, 5269.

Center of Educational Research and Development. (1997). Lebanese national curriculum and its objectives. Beirut, Lebanon: Center of Educational Research and Development and Ministry of Education and Higher Education.

Doerr, H. M., \& English, L.D. (Mar., 2003). A modeling perspective on students' mathematical reasoning about data. Journal for Research in Mathematics Education, 34 (2), 110-136.

Foster, P. (2002). Graphing: An area which consistently gives students great difficulty. The Australian Mathematics Teacher, 58 (2), 18-20.

Jackson, J., Dukerich, L., \& Hestenes D. (2008). Modeling instruction: An effective model for science education. Science Educator, 17 (1), 10-17.

Jammal, N., Dagher, H., Dakroub, R., Ghazali, B. (2000). Life and earth sciences $7^{\text {th }}$ grade: Teacher's guide. Beirut, Lebanon: Center of Educational Research and Development and Ministry of Education and Higher Education. 
Lehrer, R., \& Schauble, L. (2000). Modeling in mathematics and science. Advances in instructional psychology: Educational design and cognitive science, 5, (pp. 101-159). Mahwah, NJ: Lawrence Erlbaum Associates.

Lehrer, R., \& Schauble, L. (2002). Investigating real data in the classroom: Expanding children's understanding of math and science, (Ed.). New York, NY: Teachers College Press.

Lehrer, R., \& Schauble, L. (2004). Modeling natural variation through distribution. American Educational Research Journal, 41 (3), 635-679.

Lehrer, R., Schauble, L., \& Petrosino, A. J. ( 2001). Reconsidering the role of experiment in science education. Designing for science: Implications from everyday, classroom, and professional settings (pp. 251-277). Mahwah, N.J.: Lawrence Erlbaum Associates.

Mendez, E. P., Sherin, M.G., \& Louis, D.A. (2007). Multiple perspectives on the development of an eighth-grade mathematical discourse community. The Elementary School Journal, 108 (1), 41-61.

Monteiro, C., \& Ainley, J. (2003). Developing critical sense in graphing. European Research in Mathematics Education III.

Schwarz, C., \& White, B. (2005). Metamodeling knowledge: Developing students' understanding of scientific modeling. Cognition and Instruction, 23 (2), 165-205.

Shah, P., \& Hoeffner J. (2002). Review of graph comprehension research: Implications for instruction. Educational Psychology Review, 14 (1), 47-69. 
Treagust, D. F. (2007). General instructional methods and strategies. In S.K. Abell \& N.G.

Lederman (Eds.), Handbook of research in science education (pp. 373-392). Mahwah, N.J.: Lawrence Erlbaum Associates.

White B. (1998). Computer micro-worlds and scientific inquiry: An alternative approach to science education. In B.J. Fraser \& K.G. Tobin (Eds.), International handbook of science education, (pp.295-315). Dordrecht, The Netherlands: Kluwer. 


\section{Appendix A}

Lehrer's Data display construct

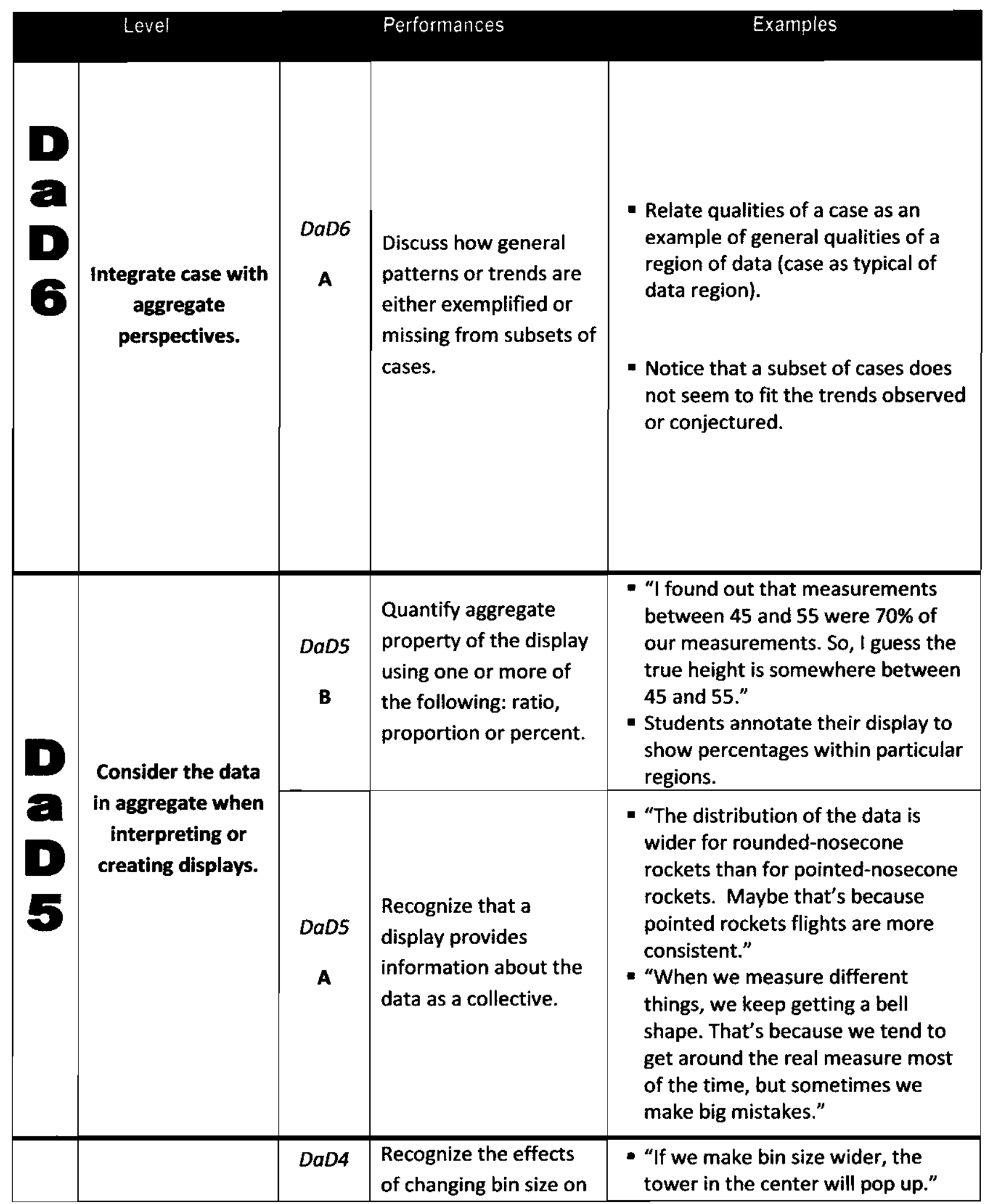




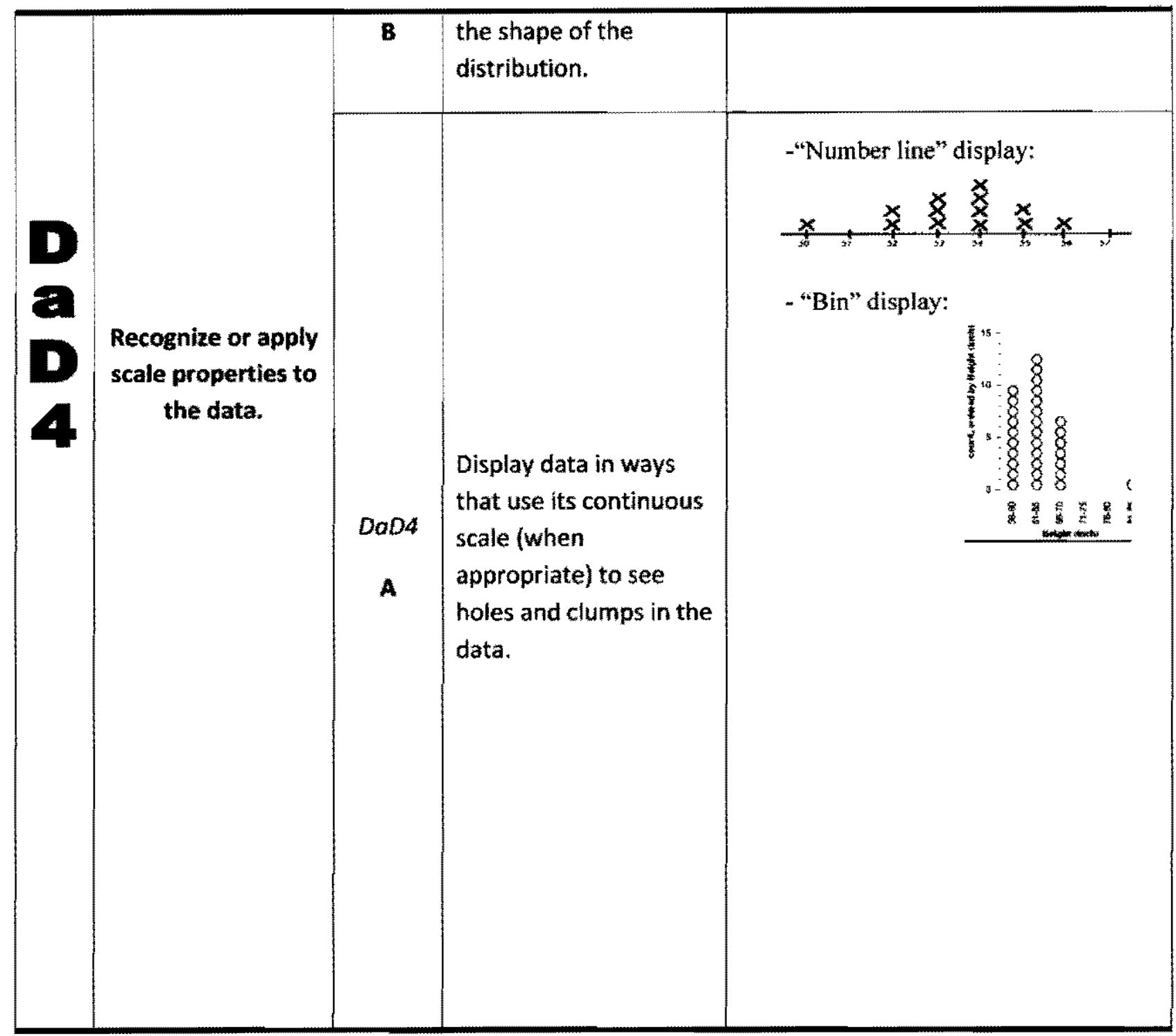

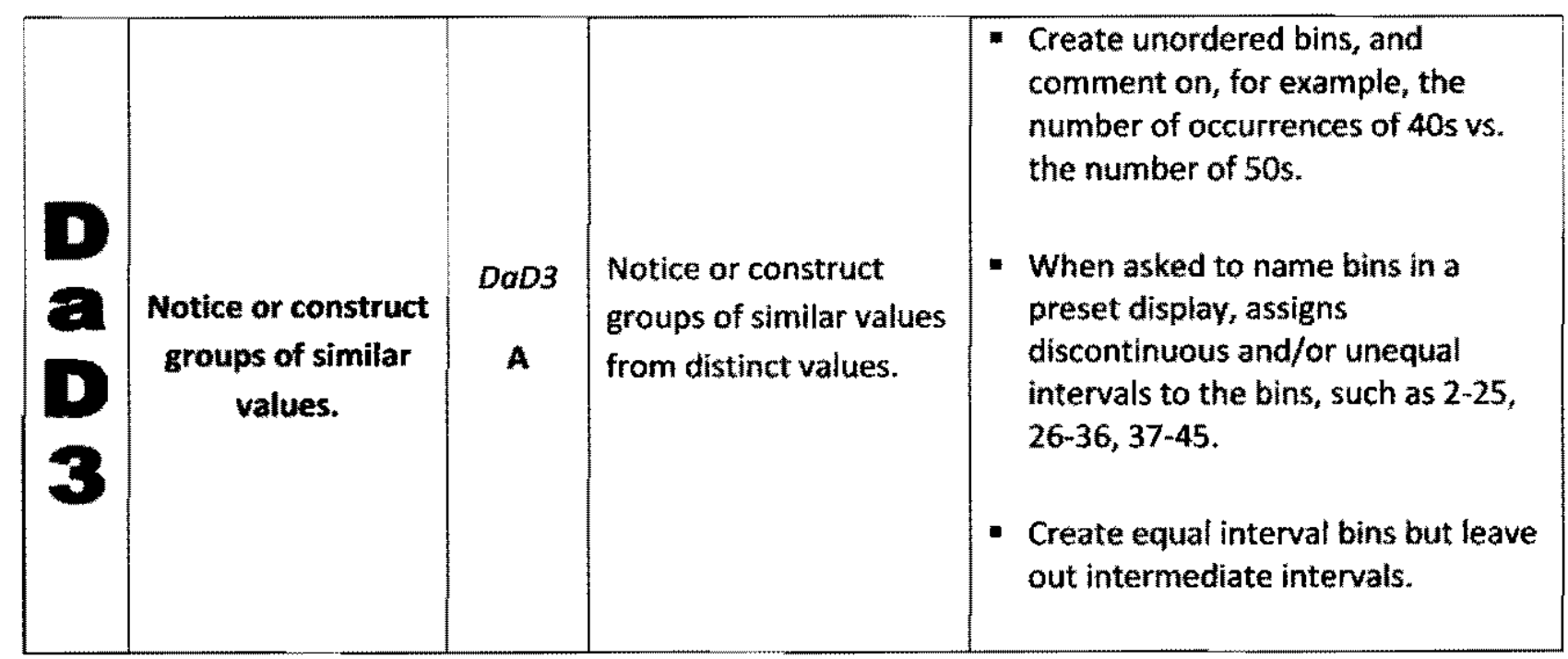




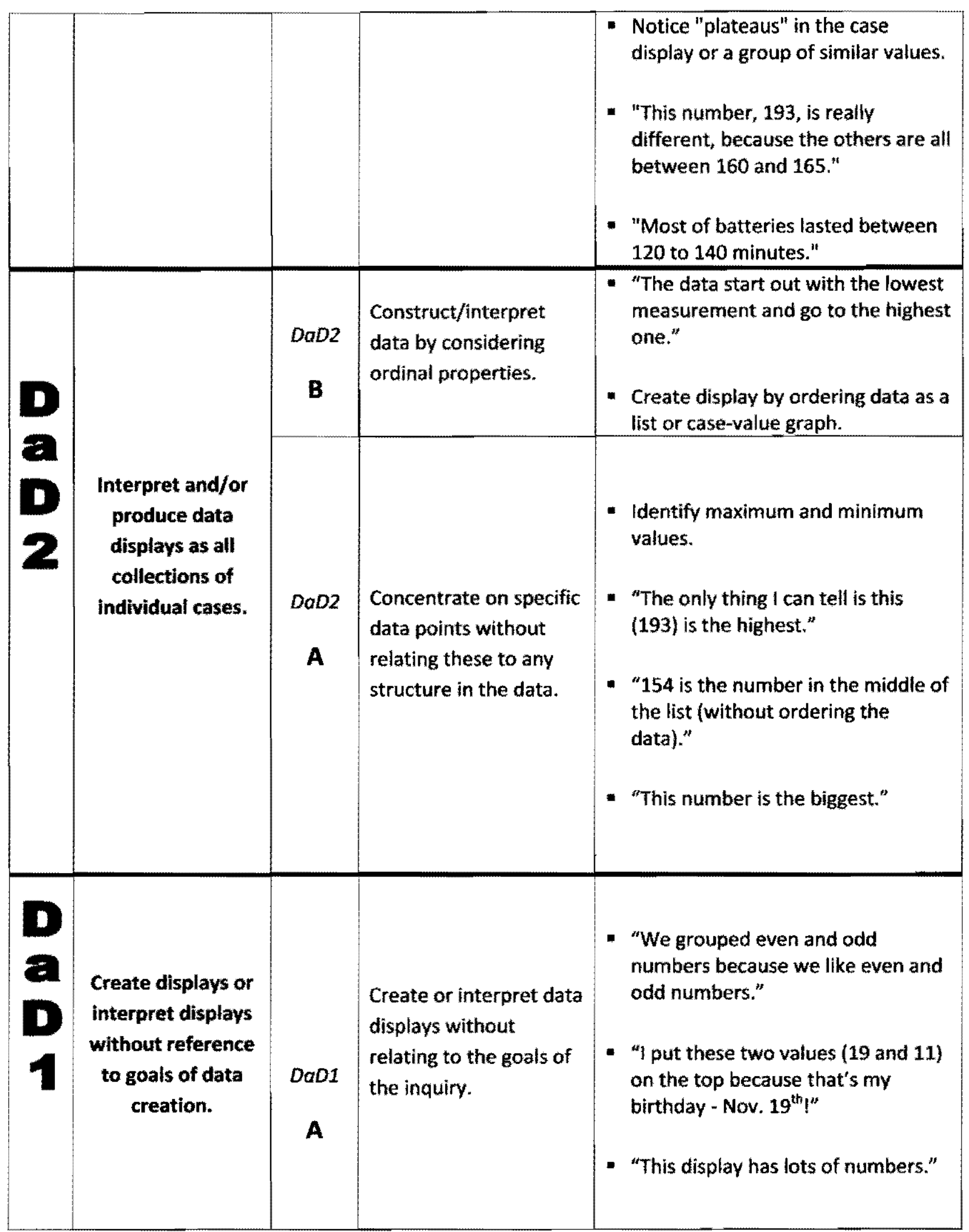


Appendix B

Pretest and Rubric

\section{Grade level: 7}

Subject: Biology

\section{Duration: $60 \mathrm{~min}$}

\section{Name:}

\section{Date:}

A. Sam is a seventh grader who walks to school every morning. At the beginning of the year Sam wanted to know at what time to leave home in order to reach school early. Therefore he studied the distance covered in meters as a function of time in minutes. The following graph (data display) was reproduced by Sam to represent his data.

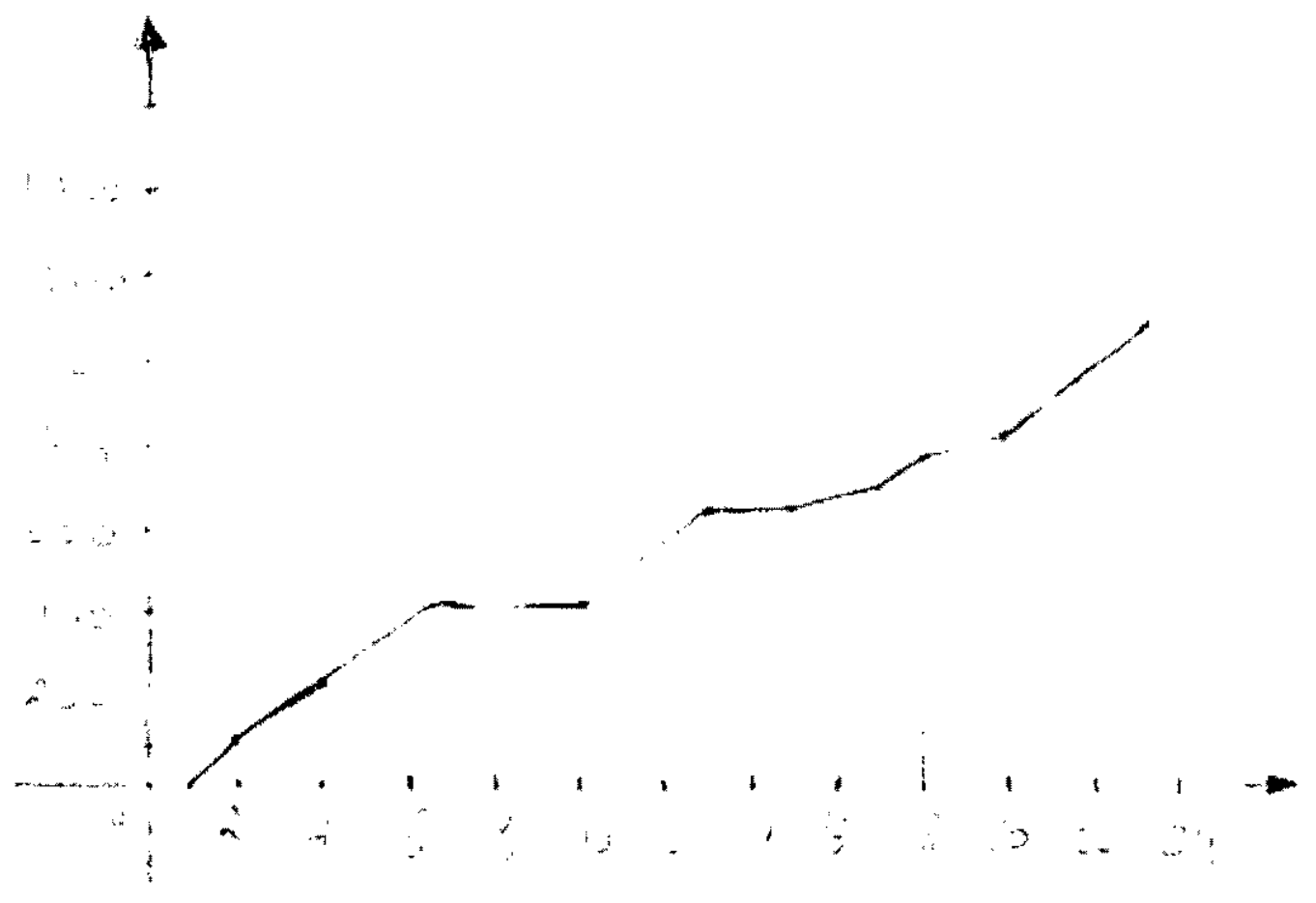

Observe the above graph and answer the following:

1. What does the vertical axis represent? 
2. What does the horizontal axis represent?

3. What is the scale used?

4. How far is the school from home?

5. How much time does it take Sam to reach school from home?

B. Letty wants to lose some weight so she decided to run every day. In order to find out the relation between the running duration and the weight in $\mathrm{kg}$, Letty represented the data she collected in the following table:

\begin{tabular}{cc} 
Table 1 & \\
\hline $\begin{array}{c}\text { Running hours } \\
8\end{array}$ & Weight in kg \\
7 & 89 \\
9 & 80 \\
10.5 & 67 \\
10 & -- \\
9.5 & 76 \\
\hline
\end{tabular}

Observe the above table and complete the missing data by constructing a graph:

1. Reorganize the data in the table.

2. What are the attributes that you will represent on the $x$-axis and on the $y$-axis?

3. What is the continuous scale that you will use on each axis?

4. Construct the graph.

5. After constructing the graph, fill in the missing data in the given table.

6. What is the relation between the running hours and the weight in $\mathrm{kg}$ ? 


\section{Rubric}

Table 2

\begin{tabular}{lcc}
\hline $\begin{array}{l}\text { Question number } \\
\text { A-1, A-2 }\end{array}$ & $\begin{array}{c}\text { Lehrer's scale } \\
\text { DaD2 B }\end{array}$ & $\begin{array}{c}\text { Assigned points } \\
\text { 2pts (1pt each) }\end{array}$ \\
A3 & DaD4 A & 2pts \\
A-4, A-5 & DaD3 A & 3pts (1.5pt each) \\
B-1, B-2 & DaD2 B & 2pts (1pt each) \\
B-3 & DaD4 A & 2pts \\
B-5 & DaD3 A & $1.5 p t s$ \\
B-6 & DaD5A & $3 p t s$ \\
B-4 & - & $2.5 p t s$ \\
\hline
\end{tabular}


Appendix C

Post-test and Rubric

\section{Grade level: 7}

\section{Subject: Biology}

\section{Duration: $60 \mathrm{~min}$}

\section{Name:}

Date:

A. Circle the right answer:

1. The lizard's skin color is light in sunlight in order to:
a) prevent an increase in its body temperature.
b) allow it to capture heat.
c) keep predators away from it.

2. The lizard's internal temperature is dependent on:
a) its activity.
b) the external temperature.
c) the external humidity.

3. A lizard is a:
a) poikilotherm
b) homiotherm 

c) mammal

4. A cat has a internal temperature.
a) variable
b) stable
c) both $a$ and $b$

5. The food and oxygen consumption of a homiotherm increase when the external temperature
a) increases
b) decreases

B. In one biology class students were asked to construct a line graph that represents the variation of food consumption in grams in an animal $x$ as a function of the external temperature in ${ }^{\circ} \mathrm{C}$ on day 1 . One of the students produced the following graph:

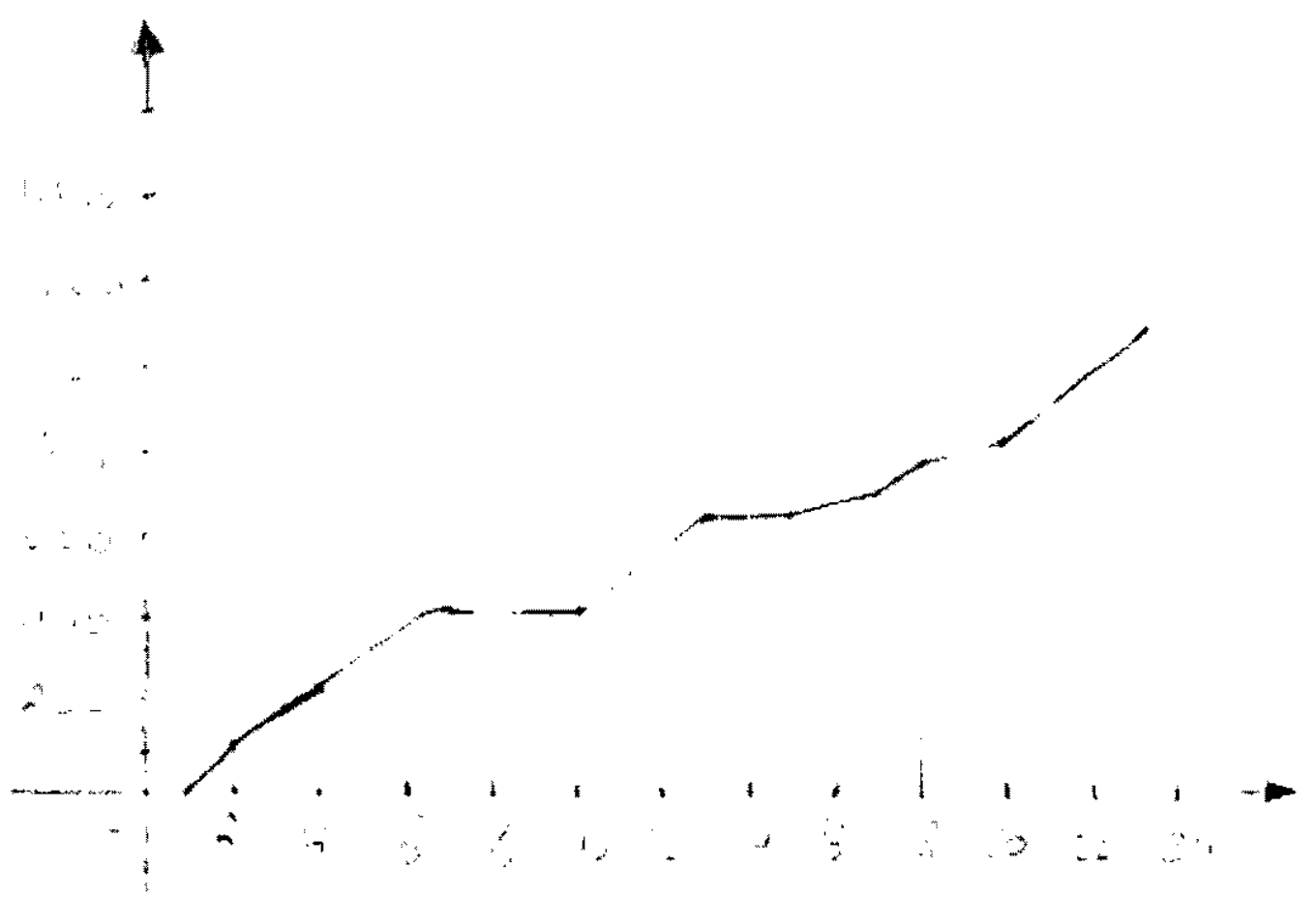


Observe the above graph and answer the following:

1. What is missing in this data display that makes it clearer?

2. What is the scale used on the $x$-axis? On the $y$-axis?

3. How many grams of food did animal $x$ eat on day 1 ?

4. At what temperature is animal $x$ not eating?

5. At what temperature is animal $x$ eating the maximum amount of food?

6. What do you conclude concerning the relation between the external temperature and animal $\mathbf{x}$ food consumption? Is it a homiotherm or a poikilotherm?

C. A scientist wanted to study the effect of the external temperature on an animal's internal temperature that he found in his backyard.

1. What is the question that he raises in order to perform the experiment on this animal?

2. The following tabulated data is what he represented after performing the experiment:

Table 3

\begin{tabular}{lcc}
\hline Time of the day & $\begin{array}{c}\text { External temperature in }{ }^{\circ} \mathrm{C} \\
\text { 2:30 pm }\end{array}$ & $\begin{array}{c}\text { Lizard's internal temperature } \\
\text { in }{ }^{\circ} \mathrm{C}\end{array}$ \\
$8: 00 \mathrm{am}$ & 35 & 33 \\
$10: 00 \mathrm{am}$ & 10 & 8 \\
$9: 00 \mathrm{am}$ & 20 & -2 \\
$11: 30 \mathrm{am}$ & 15 & 17 \\
$2: 00 \mathrm{pm}$ & 25 & 31 \\
$1: 00 \mathrm{pm}$ & 32 & 33 \\
$3: 00 \mathrm{am}$ & 30 & $\cdots$ \\
\hline
\end{tabular}

Observe the above table and complete the missing data by constructing a graph:

a) Reorganize the data in a 2-column table.

b) What are the attributes that you will represent on the $x$-axis and on the $y$-axis?

c) What is the continuous scale that you will use on each axis?

d) Construct the graph. 
e) After constructing the graph, fill in the missing data in the given table.

f) What do you notice about the shape of the graph when the external temperature is $32^{\circ} \mathrm{C}$ and above? What is it called?

g) Find an answer to the question you posed in part C-1.

\section{Rubric}

\begin{tabular}{|c|c|c|}
\hline $\begin{array}{l}\text { Question number } \\
\text { A (Knowledge) }\end{array}$ & Lehrer's scale & $\begin{array}{l}\text { Assigned points } \\
5 \text { pts (lpt each) }\end{array}$ \\
\hline B-1 & $\mathrm{DaD} 2 \mathrm{~B}$ & $1 \mathrm{pts}$ \\
\hline B-2 & DaD4 A & $2 \mathrm{pts}$ \\
\hline$B-3, B-4, B-5$ & DaD3 A & $4.5 \mathrm{pts}$ (1.5pt each) \\
\hline B-6 & DaD5A & $3 \mathrm{pts}$ \\
\hline $\mathrm{C}-1$ & $-\cdots$ & $1 \mathrm{pt}$ \\
\hline $\mathrm{C}-2 \mathrm{a}, \mathrm{C}-2 \mathrm{~b}$ & $\mathrm{DaD} 2 \mathrm{~B}$ & $2 p t s$ (1pt each) \\
\hline $\mathrm{C}-2 \mathrm{c}$ & $\mathrm{DaD} 4 \mathrm{~A}$ & 2pts \\
\hline$C-2 d$ & $-\cdots$ & $2.5 \mathrm{pts}$ \\
\hline $\mathrm{C}-2 \mathrm{e}$ & $\mathrm{DaD} 3 \mathrm{~A}$ & $1.5 \mathrm{pts}$ \\
\hline $\mathrm{C}-2 \mathrm{f}$ & $\mathrm{DaD} 3 \mathrm{~A}$ & $1.5 \mathrm{pts}$ \\
\hline C- $2 \mathrm{~g}$ & DaD5A & $3 \mathrm{pts}$ \\
\hline
\end{tabular}




\section{Appendix D}

Total number of points assigned for each data display level in each test.

\section{Table 5}

Data display level

DaD2B

DaD3A

DaD4A

DaD5A Total number of points in pretest

4

4.5

4

3
Total number of points in post-test.

3

7.5

4

6 